\title{
Transient antibody targeting of CD45RC induces transplant tolerance and potent antigen-specific regulatory $T$ cells
}

\author{
Elodie Picarda, ${ }^{1,2}$ Séverine Bézie, , ${ }^{1,2}$ Laetitia Boucault,, ${ }^{1,2}$ Elodie Autrusseau, ${ }^{1,2}$ Stéphanie Kilens, ${ }^{1,2}$ \\ Dimitri Meistermann, ${ }^{1,2}$ Bernard Martinet, ${ }^{1,2}$ Véronique Daguin, ${ }^{1,2}$ Audrey Donnart, ${ }^{3}$ \\ Eric Charpentier, ${ }^{3}$ Laurent David, ${ }^{1,2}$ Ignacio Anegon, ${ }^{1,2}$ and Carole Guillonneau ${ }^{1,2}$ \\ 'Centre de Recherche en Transplantation et Immunologie UMR1064, INSERM, Université de Nantes, Nantes, France. \\ ${ }^{2}$ Institut de Transplantation Urologie Néphrologie (ITUN), CHU Nantes, Nantes, France. ${ }^{3}$ INSERM UMR1087, CNRS \\ UMR6291, Université de Nantes, l'institut du thorax, Nantes, France.
}

Rat and human CD4+ and CD8+ Tregs expressing low levels of CD45RC have strong immunoregulatory properties. We describe here that human CD45 isoforms are nonredundant and identify distinct subsets of cells. We show that CD45RC is not expressed by CD4 ${ }^{+}$and CD8 ${ }^{+}$ Foxp3+ Tregs, while CD45RA/RB/RO are. Transient administration of a monoclonal antibody (mAb) targeting CD45RC in a rat cardiac allotransplantation model induced transplant tolerance associated with inhibition of allogeneic humoral responses but maintained primary and memory responses against cognate antigens. Anti-CD45RC mAb induced rapid death of CD45RChigh $T$ cells through intrinsic cell signaling but preserved and potentiated $C D 4^{+}$and $C D 8^{+}$CD45RClow/- Tregs, which are able to adoptively transfer donor-specific tolerance to grafted recipients. Anti-CD45RC treatment results in distinct transcriptional signature of $\mathrm{CD4}^{+}$and $\mathrm{CD8} 8^{+} \mathrm{CD} 45 \mathrm{RC}^{\text {low/- }}$ Tregs. Finally, we demonstrate that anti-human CD45RC treatment inhibited graft-versus-host disease (CVHD) in immune-humanized NSG mice. Thus, short-term anti-CD45RC is a potent therapeutic candidate to induce transplantation tolerance in human.

Authorship note: $E P, S B$, and LB contributed equally to this report. IA and CG are co-senior authors.

Conflict of interest: CG and IA have submitted a patent (W02016016442) that is pending.

Submitted: August 12, 2016

Accepted: December 22, 2016

Published: February 9, 2017

Reference information:

JCI Insight. 2017;2(3):e90088. https://doi.org/10.1172/jici.

insight.90088.

\section{Introduction}

Organ transplantation requires immunosuppression to prevent rejection of the grafted organ. A major goal in transplantation to enhance a grafted patient's life would be to induce a long-term tolerance with a transient treatment. To achieve this goal, work has been done to design treatments that would mediate an acceptance of the graft antigens by promoting Tregs specific of those antigens. In contrast to immunosuppressive drugs, Treg-mediated tolerance would preserve patients' immunity, thus decreasing the risk of cancer and infections $(1,2)$. Therefore, the identification of cellular targets for monoclonal antibody $(\mathrm{mAb})$ therapies to provide a specific rather than a general immunosuppression associated with the induction of Tregs represents a major objective, and such therapies have shown potential in autoimmune diseases $(3,4)$. However, to date, there is no therapy with these properties in the clinic and particularly in transplantation (2).

The transmembrane tyrosine phosphatase CD45 protein is an essential regulator of $\mathrm{T}$ and $\mathrm{B}$ cell antigen receptor signaling in the immunological synapse by negatively and positively tuning the activity of either Lck in T cells or Lyn, Fyn, and Lck in B cells (5-7). Several isoforms of the CD45 protein are generated by alternative splicing of exons 4-6 encoding extracellular domains $\mathrm{A}, \mathrm{B}$, and $\mathrm{C}$, or $\mathrm{O}$ in the absence of the 3 exons (i.e., CD45RA, CD45RB, CD45RC, and CD45RO) and conferring differences in size and charge $(8,9)$. Individuals express different levels of CD45 isoforms (10). While the function of CD45 isoforms remains unclear, their differential expression has been associated with T cell activation's level. The most analyzed CD45RA and CD45RB isoforms are mainly expressed by naive $\mathrm{T}$ cells and terminally differentiated effector memory (TEMRA) cells, while the shortest isoform, CD45RO, is expressed by activated/memory T cells $(5,11-13)$. The expression of the CD45RC isoform has been described in rats. Both $\mathrm{CD} 4{ }^{+} \mathrm{CD} 45 \mathrm{RC}^{\text {high }}$ and $\mathrm{CD} 8^{+} \mathrm{CD} 45 \mathrm{RC} \mathrm{C}^{\text {high }} \mathrm{T}$ cells are potent $\mathrm{Th} 1$ effector cells, promoting transplant rejection and organ inflammation, while $\mathrm{T}$ cells with no/low expression of CD45RC have a Th2 or regulatory phenotype, inhibiting solid allograft rejection, graft-versus-host 
disease (GVHD), and cell-mediated autoimmune diseases (14-19). We have shown in a rat model of organ transplantation tolerance that antigen-specific regulatory $\mathrm{CD} 8^{+} \mathrm{CD} 45 \mathrm{RC} \mathrm{C}^{\text {low }}-\mathrm{T}$ cells transferred dominant donor-specific tolerance associated with production of IFN $\gamma$, fibroleukin-2, and IL-34 (18, 20-24). In humans, a high proportion of $\mathrm{CD} 45 \mathrm{RC} \mathrm{hin}^{\text {high }} \mathrm{CD} 8^{+} \mathrm{T}$ cells before transplantation has been correlated with decreased graft survival in kidney transplanted patients (25). The subset of human $\mathrm{T}$ cells expressing CD45RC exhibits cytokine profiles after polyclonal stimulation, similarly to rats (10).

We thus reasoned that depleting $\mathrm{CD} 45 \mathrm{RC} \mathrm{C}^{\text {high }}$ cells with a short course of anti-CD45RC treatment would enrich for $\mathrm{CD} 45 \mathrm{RC}^{\text {low/-}} \mathrm{CD} 4^{+}$and $\mathrm{CD} 8^{+}$Tregs, and we evaluated the effect in transplantation models. We demonstrated that an antibody-mediated specific death induction of CD45RC ${ }^{\text {high }}$ cells was able to induce donor-specific dominant tolerance transferrable to secondary recipients by functionally potentiated $\mathrm{CD}^{+} \mathrm{CD} 45 \mathrm{RC}^{\text {low } /-}$ and $\mathrm{CD} 8{ }^{+} \mathrm{CD} 45 \mathrm{RC}^{\text {low/- }}$ Tregs. Transcriptome analysis revealed that immune memory was associated with regulation of a subset of genes. Treated recipients were able to mount efficient naive and memory responses against cognate antigens, while anti-donor humoral responses were completely inhibited. We demonstrated here that human Foxp $3^{+} \mathrm{CD}^{+}$and Foxp3 ${ }^{+} \mathrm{CD} 8^{+}$Tregs are largely CD45RC ${ }^{\text {low/- }}$, while expressing other isoforms. Thus, anti-CD45RC mAb treatment could be applicable to humans, as ex vivo $\mathrm{CD} 45 \mathrm{RC}^{\text {high }}$ cell depletion of PBMCs or short-term in vivo administration of anti-human CD45RC $\mathrm{mAb}$ protected from or significantly delayed GVHD in humanized NSG mice.

These findings demonstrate that short-term $\mathrm{CD} 45 \mathrm{R} \mathrm{C}^{\text {high }}$ targeting is a potent therapeutic candidate to induce donor-specific Treg-mediated tolerance in transplantation and that CD45RC is a new immune checkpoint at the interface of effector/regulatory responses.

\section{Results}

Transient anti-CD45RC $m A b$ treatment induces donor-specific transplant tolerance in a fully mismatched cardiac allograft model in the rat, while preserving general immunity. We first assessed CD45RC expression in the rat to fully understand the pattern of expression of this isoform of the CD45 molecule and the potential cell subsets targeted by an anti-CD45RC mAb treatment (Figure 1A and Supplemental Figure 1; supplemental material available online with this article; https://doi.org/10.1172/jci.insight.90088DS1). We observed that CD45RC is expressed by all B cells and plasmacytoid DCs (pDCs), as well as by $40 \%-75 \%$ of CD $4^{+}$ and $\mathrm{CD}^{+} \mathrm{T}$ cells, NK cells, NKT cells, monocytes, granulocytes, $\mathrm{CD} 4^{+}$conventional DCs (cDCs), and CD4- ${ }^{-}$DCs (Figure 1A). In contrast $\mathrm{CD}^{+} \mathrm{CD} 25^{+} \mathrm{CD} 127^{-} \mathrm{Foxp}^{+}$Tregs were negative for this marker, and we have already described in the past that $\mathrm{CD} 8^{+}$Tregs are within $\mathrm{CD} 45 \mathrm{RC}^{\text {low/- }}$ cells $(18,21,22)$.

We next assessed CD45RChigh cell targeting using anti-CD45RC mAb to enrich in $\mathrm{CD}^{+}$or $\mathrm{CD}^{+}$ $\mathrm{CD} 45 \mathrm{RC}^{\text {low/- }}$ Tregs and promote tolerance in cardiac-transplanted recipients. Administration of mouse IgG1 anti-rat CD45RC mAb (clone OX22) for 10 or 20 days to transplanted rat recipients (complete MHC mismatched, LEW.1W $\rightarrow$ LEW.1A) (Figure 1B) led to indefinite allograft survival in $83.3 \%(n=6)$ and $62.2 \%(n=9)$ of recipients, respectively, in contrast to recipients treated for 5 days (median survival $=14$ days), and it compared with control untreated or control recipients administered with control isotype mAb for 20 days (median survival $=7$ days for both) (Figure 1B). We challenged the tolerogenic potential of the anti-CD45RC $\mathrm{mAb}$ by switching the donor/recipient combination (LEW.1A $\rightarrow$ LEW.1W), which results in a stronger acute rejection (mean survival time $[\mathrm{MST}] \pm \mathrm{SEM}=7 \pm 0$ vs. $7.8 \pm 1.7$ for $\mathrm{W} \rightarrow \mathrm{A}$ ). In this graft combination, CD45RC-specific $\mathrm{mAb}$ resulted in indefinite allograft survival in all recipients (Figure $1 \mathrm{~B}$, A/W). Cardiac graft histopathology analysis revealed a complete absence of fibrosis, immune cell infiltrate, and vessel intimal thickening at day 120 in 100\% of anti-CD45RC-treated long-surviving recipients, similarly to syngeneic graft, and it compared with day 120 control recipients that developed chronic rejection (Figure 1C), demonstrating that transient anti-CD45RC treatment inhibits acute and chronic rejection and induces active mechanisms of true tolerance after treatment is stopped. We observed a complete absence of anti-donor IgG, IgG1, IgG2a, and IgG2b antibodies in sera of day-120 anti-CD45RC mAb-treated recipients compared with untreated rats that had rejected their graft; antibody levels were comparable to levels observed in naive rats (Figure 1D), demonstrating that anti-donor immune responses were fully inhibited, even long-term, following treatment.

Importantly, anti-CD45RC mAb-treated tolerant recipients immunized at day 120 with Keyhole limpet hemocyanin $(\mathrm{KLH})$ (Figure 2A) resulted in production of anti-KLH IgM and IgG Ab comparable with immunized controls, demonstrating that recipients' immune responses were normal after treatment. In addition, rats immunized with horse red blood cells (HRBC) 7 days prior to transplantation and anti-CD45RC 
A

CD4+
T cells

CD8+

T cells

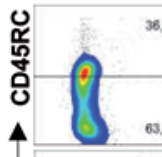

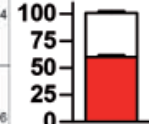

NKT cells
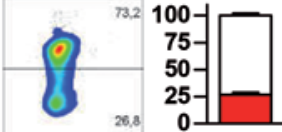

B cells

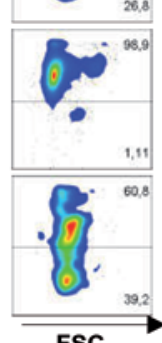

75

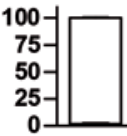

Granulocytes

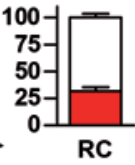

B

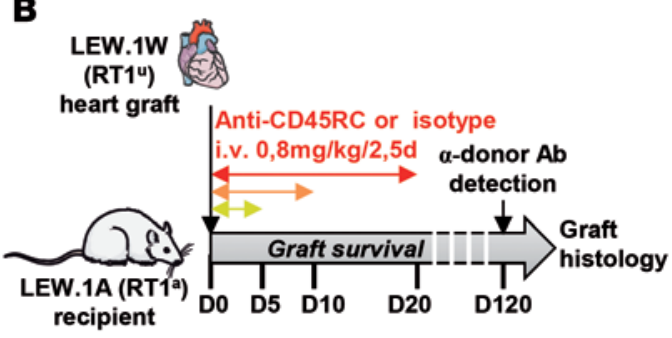

NK cells

Monocytes

pDC
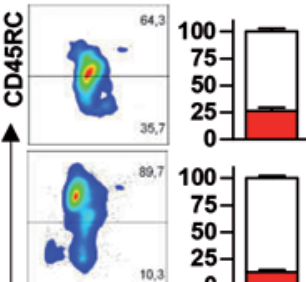

-
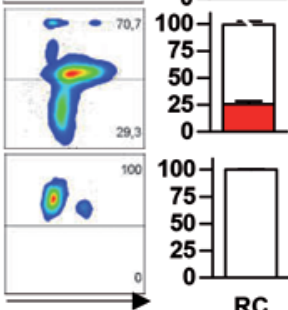

FSC
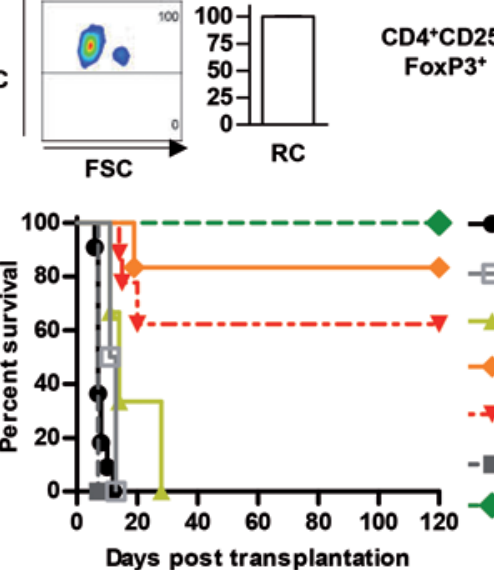

FSC

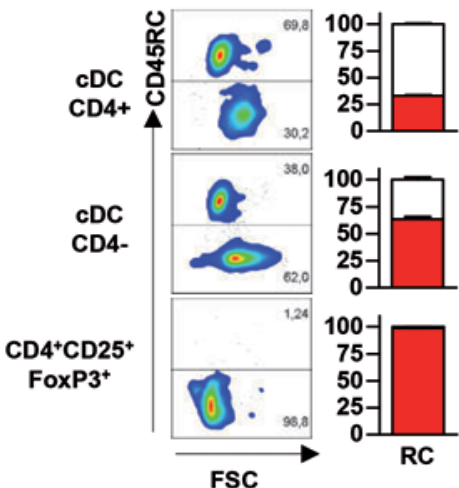

C
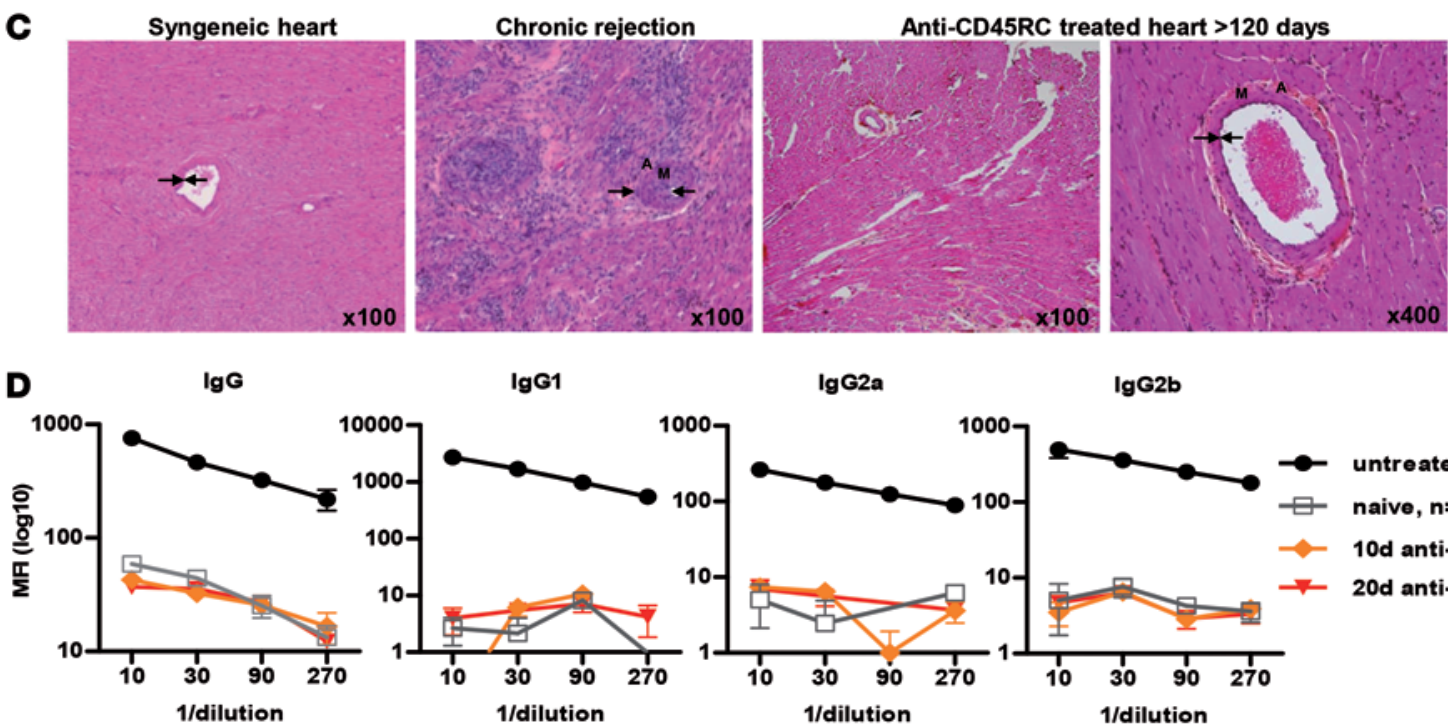

$\lg 62$

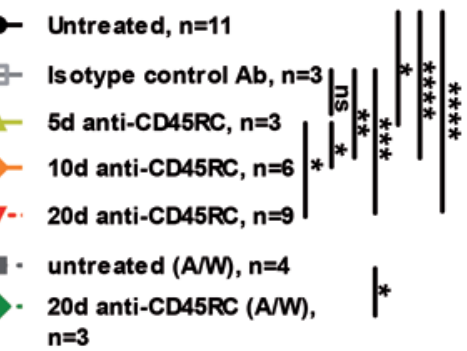

(19)

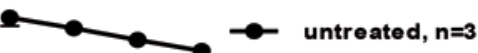

曰 naive, $n=3$

10d anti-CD45RC, 20d anti-CD45RC,

Figure 1. Transient anti-CD45RC mAb treatment induces donor-specific transplant tolerance in a fully mismatched cardiac allograft model in the rat. (A) Analysis of CD45RC expression on rat peripheral blood PBMCs. CD4+ and CD8+ T cells, B cells, NK cells, NKT cells, monocytes, granulocytes, pDCs, $\mathrm{CD}^{+}$or $\mathrm{CD} 4^{-} \mathrm{CDCs}$, and $\mathrm{CD} 4^{+} \mathrm{CD} 25^{+}$Foxp3 ${ }^{+}$Tregs were analyzed for CD45RC marker expression by flow cytometry. Left: A representative experiment of 6 rats. Right: Mean expression \pm SEM of CD45RC or CD45RC ${ }^{\text {low/- }}$ in each cell population. (B) Left: Model depicting allograft transplantation in MHC-incompatible rats, antibody treatment, and monitoring. Right: Recipients were either untreated $(n=11)$ or treated 5 days $(n=3), 10$ days $(n=6)$, or 20 days $(n=9)$ in the LEW.1W/LEW.1A strain combination or treated 20 days in the more stringent LEW.1A/LEW.1W strain combination. Log rank (Mantel Cox) test, ${ }^{*} P<0.05,{ }^{* *} P<0.01,{ }^{* * *} P<0.001,{ }^{* * *} P<0.0001$. (C) Representative histological analysis of graft for signs of chronic rejection lesions performed at $>120$ days on syngeneic graft recipient, allogeneic long-term chronic rejection graft recipient, and anti-CD45RC-treated recipients at magnification $\times 100$ and $\times 40$. A, Adventitia; M, Media. The arrows show the intima wall. (D) IgG, IgG1, IgG2a, or lgG2b alloantibody production was evaluated in naive, untreated, 10-day, and 20-day anti-CD45RC-treated animals $>120$ days after transplantation ( $n=3$ for all groups). Graph represents MFI \pm SEM. Two-way repeated measures ANOVA, ${ }^{* *} P<0.01$. 
$\mathrm{mAb}$ (or isotype control) treatment and reimmunized at day 3 (Figure 2B) developed humoral responses toward HRBC exogenous antigens, comparable with controls. To prove the capacity of recipients to mount $\mathrm{B}$ cell responses during the treatment, we analyzed the kinetic of $\mathrm{Ab}$ production in the sera of the same recipients (Figure $2 \mathrm{C}$ ). Indeed, if $\mathrm{Ab}$ detected in the sera of anti-CD45RC mAb-treated recipients at day 13 would be due to remaining $\operatorname{IgM}$ and $\operatorname{IgG}$ in the sera from the primary immune response from day -7 , levels of $\mathrm{Ab}$ following immunization at day 3 should not increase. Kinetic of the 1 st immunization demonstrated a peak 7 days after the immunization (day 0) of anti-HRBC IgG Ab in the sera of either isotype control- or anti-CD45RC mAb-treated rats followed by a decrease 10 days after immunization (day 3) (Figure 2C). Following the second immunization at day 3, we observed a substantial increase in IgG anti-HRBC Ab production in isotype control- or anti-CD45RC mAb-treated rats, with an increase of almost 2-fold of the 1 st immunization, demonstrating that the recipients had consistently developed new Ab toward exogenous antigens and that, thus, the T cell-dependent memory B cell response was unchanged.

To definitely prove that $\mathrm{T}$ cell-dependent $\mathrm{B}$ cell responses were not affected by anti-CD45RC $\mathrm{mAb}$ treatment, we assessed the capacity of recipients immunized with $\mathrm{KLH}$ and CFA 3 days after the initiation of the 10-day anti-CD45RC mAb or isotype control treatment to mount new immune responses (Figure 2D). Measurement of anti-KLH IgG Ab 14 days following immunization demonstrated that anti-CD45RC $\mathrm{mAb}$-treated recipients were able to mount humoral immune responses as efficiently as controls.

Altogether, we demonstrated that short-term anti-CD45RC mAb treatment resulted in transplant tolerance associated with a specific total inhibition of anti-donor humoral responses, without compromising new or memory humoral immunity against cognate antigens.

Transient anti-CD $45 R C \mathrm{mAb}$ treatment induces rapid cell death of $C D 45 R C^{\text {high }}$ target $T$ cells through an intrinsic pathway while preserving and potentiating $C D 45 R C^{\text {low/- }}$ Tregs. We next analyzed in vivo the effect of anti$\mathrm{CD} 45 \mathrm{RC} \mathrm{mAb}$ on leukocyte subpopulations in the blood of 10-day anti-CD45RC-treated recipients during the early (days $4,10,15$ ) and late time point (day 120) following transplantation (Figure 3, A-C). To detect expression of CD45RC, we used distinct anti-CD45RC mAb (clones OX22, OX32, or 3H1437) and observed that $\mathrm{OX} 22^{+}$cells are also all $\mathrm{OX} 32^{+}$or $3 \mathrm{H} 1437^{+}$, demonstrating the specificity of OX22 clone to $\mathrm{CD} 45 \mathrm{RC}$ and also showing that the three distinct $\mathrm{mAb}$ recognized distinct epitopes of the CD45RC molecule (Supplemental Figure 2). Anti-CD45RC mAb injection resulted in a transient but significant reduction of $\mathrm{CD} 45 \mathrm{RC}^{\text {high }} \mathrm{CD} 4^{+}$and $\mathrm{CD} 8^{+} \mathrm{T}$ cells at day 4 , still marked at day 10 and day 15 (Figure $3 \mathrm{~A}$ ), and followed by a slow return to normal levels. We observed no decrease in numbers of B, NKT, and NK cells or DCs, a trend for a decrease in monocytes at day 4, but we observed a significant increase at day 10 of $\mathrm{B}$ and NKT cells in the blood (Figure 3B), followed by a rapid return to normal levels. Since tolerance was maintained long-term after arrest of the treatment, we analyzed the numbers of Treg subsets, as previously described (22) (Figure 3C). We observed a significant increase in absolute numbers of CD45RClow/$\mathrm{CD}^{+}$and $\mathrm{CD}^{+} \mathrm{T}$ cell subsets among PBMCs at day 10. CD45RC-specific mouse antibody injection was associated at day 13 with humoral responses toward mouse anti-CD45RC, likely explaining the rapid reappearance of target cells - the higher level of B cells observed on day 10 - demonstrating the absence of a depleting effect of the antibody on $\mathrm{B}$ cells and the capacity of treated rats to mount humoral response to new antigens (Figure 3D). In addition, CD45RC-specific mAb treatment did not modify leucocytes subpopulations at day 10 in the thymus, axillary, and mesenteric lymph nodes (Supplemental Figure 3, A-C); significantly decreased B cells in the BM (Supplemental Figure 3D); decreased CD4 ${ }^{+} \mathrm{T}$ cells; and increased macrophages in the spleen (Supplemental Figure 3E).

We investigated further the mechanisms of action of CD45RC-specific antibody in vitro and analyzed CD45RC $\mathrm{C}^{\text {high }}$ target $\mathrm{T}$ cells and non-T cell viability (Figure 3, E-H, and Supplemental Figure 4). CD45RC-specific antibody incubation with total splenocytes induced a significant and rapid $\mathrm{T}$ cell death, as shown by increased apoptotic markers (annexin $\mathrm{V}^{+} \mathrm{DAPI}{ }^{+}$) and total cell death $\left(\mathrm{DAPI}^{+}\right)$(Figure $3 \mathrm{E}$ and Supplemental Figure 4A), compared with dexamethasone (inducer of cell death) and isotype control $\mathrm{mAb}$. We also observed no significant induction of non-T cell death (Supplemental Figure 4B), although we observed a trend for an increase of monocyte-induced cell death (Figure 3F), but not B cells (Figure $3 G$ ), correlating with our observations in vivo (Figure 3B). Incubation of CD45RC-specific antibody with purified $\mathrm{T}$ cells depleted of $\mathrm{Fc} \gamma \mathrm{R}^{+}$cells (Supplemental Figure $4 \mathrm{C}$ ) resulted in a similar cell death induction, demonstrating that effector cells are not required for the cell death induction mediated by CD45RCspecific mAb. We analyzed the involvement of mitochondria in anti-CD45RC-mediated apoptosis by measuring mitochondrial membrane potential in live cells. We observed a significant loss of mitochondrial 
A LEW.1W (RT14)
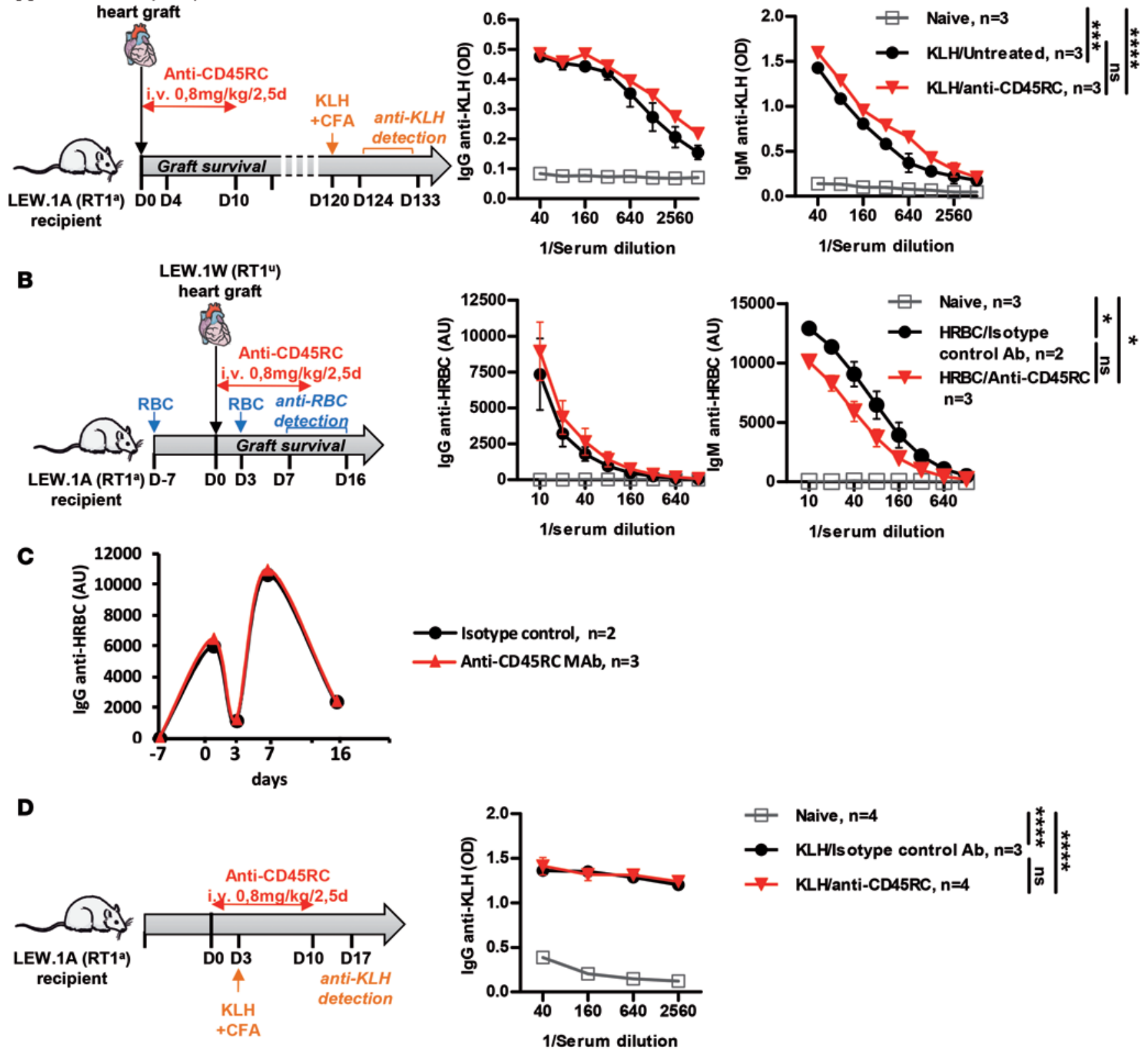

Figure 2. Transient anti-CD45RC mAb treatment preserves humoral and memory immunity toward cognate antigen. (A) Left: Model depicting memory humoral response immunization and monitoring at late time point. Right: Recipients were treated or not with anti-CD45RC for 10 days and $\mathrm{KLH}$ immunized on day 120 after transplantation, and sera were analyzed for IgM and IgC reactivity against KLH, respectively, 4 days and 13 days after immunization. Serum from naive animals was used as negative control. $n=3$ for all groups. Results are expressed as optical density \pm SEM for the indicated dilution of serum. (B) Left: Model depicting memory humoral response immunization and monitoring. Right: Recipients were immunized with HRBC 7 days before transplantation and at day 3 , and they were treated with anti-CD45RC mAb $(n=3)$ or isotype control mAb $(n=2)$ from day $0-10$. Sera were analyzed for IgM and IgC reactivity against HRBC, respectively, 4 days and 13 days after the second immunization. Serum from naive animals was used as negative control $(n=3)$. Results are expressed in MFI \pm SEM. (C) Analysis of kinetic of anti-HRBC IgC production in the sera of recipients immunized with HRBC 7 days before transplantation and at day 3 , and treated with anti-CD45RC mAb ( $n=3$ ) or isotype control mAb $(n=2)$ from day 0-10. (D) Left: Model depicting naive humoral responses immunization and monitoring during the treatment. Right: Recipients were treated or not with anti-CD45RC for 10 days and immunized at day 3 during treatment, and sera were analyzed for IgC reactivity against KLH 14 days after immunization. Serum from naive animals was used as negative control. $n=3$ for all groups. Results are expressed as optical density \pm SEM for the indicated dilution of serum. Two-way repeated measures ANOVA, ${ }^{*} P<0.05$, ${ }^{* * *} P<0.001,{ }^{* * * *} P<0.0001$. 


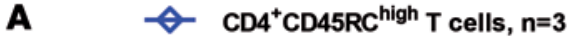
曰 CD8 $^{+}$CD45RC ${ }^{\text {high }} T$ cells, $n=3$

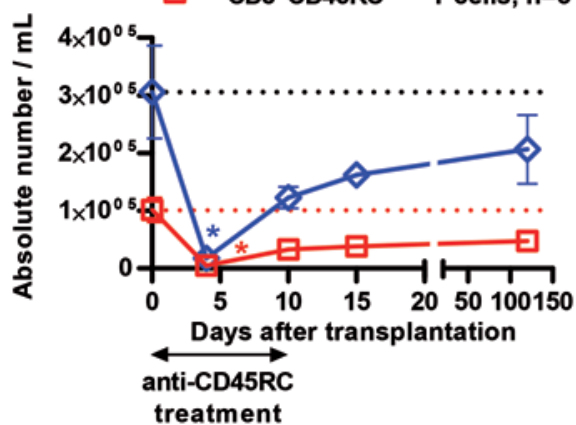

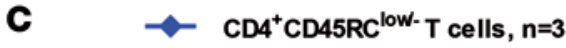
$-\mathrm{CDB}^{+} \mathrm{CD}^{-} \mathrm{CRC}^{\text {low- }} \mathrm{T}$ cells, $\mathrm{n}=3$
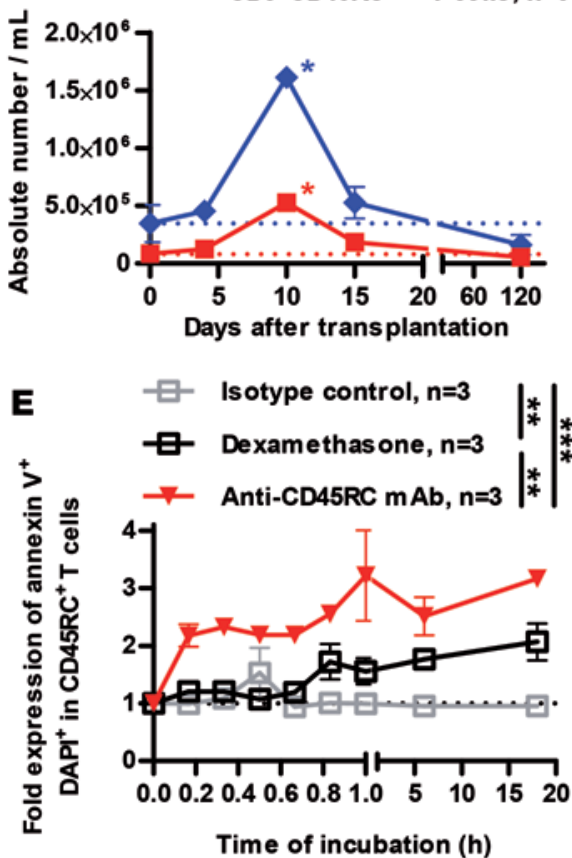

G

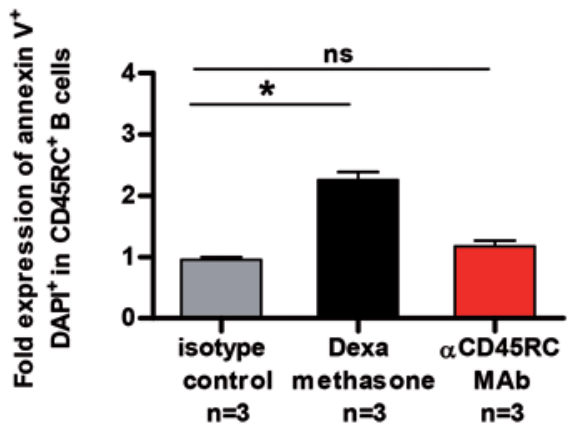

B

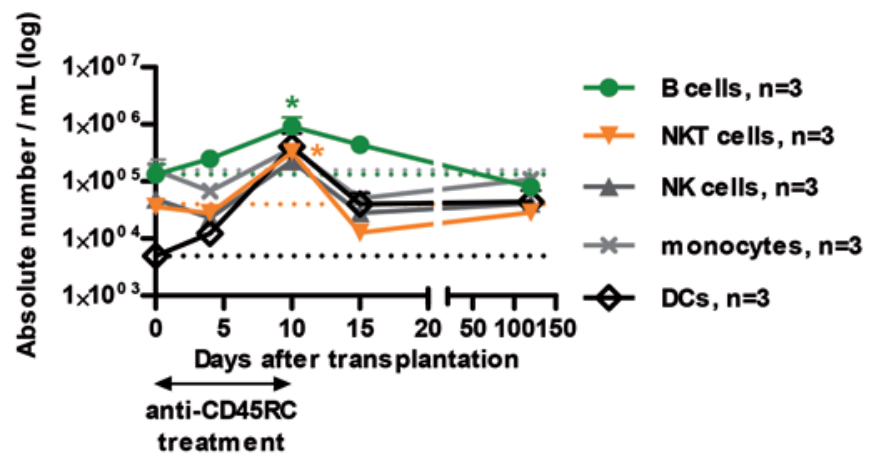

D

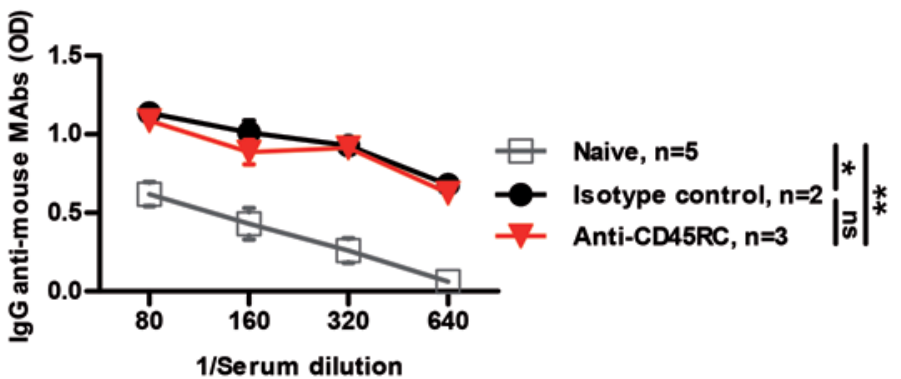

F

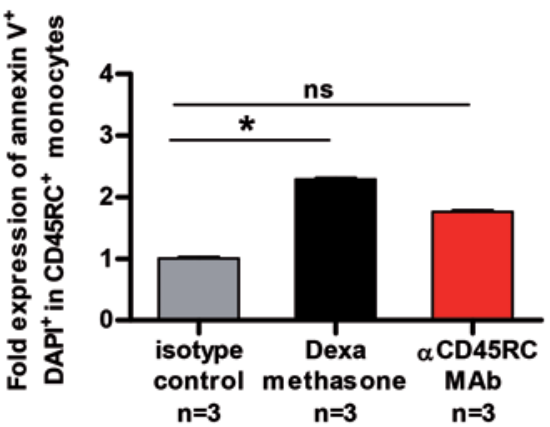

H

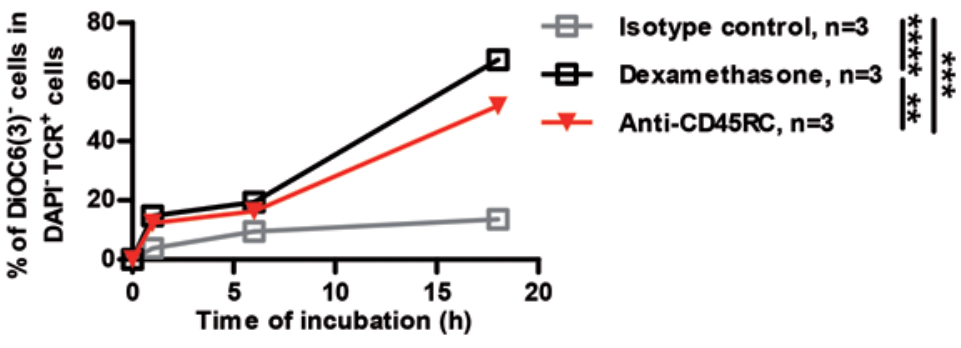

Figure 3. Transient anti-CD45RC mAb treatment induces rapid cell death of CD45RC+ $T$ cells while preserving and increasing CD45RC ${ }^{\text {low/- }}$ Tregs. PBMCs were harvested at day 0,4 , and 10 (during treatment), at day 15 ( 5 days after end of treatment), and long-term at day 120 from anti-CD45RC-treated recipients compared with naive PBMCs and analyzed by flow cytometry for absolute number of CD45RChigh T cells (A), as well as B cells, NK cells, NKT cells, monocytes, and DCs (B) or CD45RClow/- T cells (C). $n=3$ for all groups. Results are expressed as number of cells per $\mathrm{ml}$ of blood. Friedman and Dunn's post-test. ${ }^{*} P<0.05$. Dotted lines represent normal values for the cell populations corresponding to the color codes. (D) IgC antibody production against mouse mAb was measured at day 13 in the sera of animals treated 10 days with anti-CD45RC $(n=3)$ or isotype control $(n=2)$ compared with naive animal $(n=5)$. Results are expressed as optical density \pm SEM for the indicated dilution of serum. Two-way repeated measures ANOVA, ${ }^{*} P<0.05,{ }^{*} P<0.01$. (E-G) Apoptosis was analyzed on total splenocytes incubated with anti-CD45RC mAb, dexamethasone, or isotype control mAb and stained with annexin $V$ and DAPI. Results are expressed as relative proportion of annexin $\mathrm{V}^{+} \mathrm{DAPI}{ }^{+}$cells among $\mathrm{CD} 45 \mathrm{RC} \mathrm{C}^{+} \mathrm{T}$ cells for 10 min to 18 hours $(\mathbf{E})$, monocytes for 18 hours $(\mathbf{F})$, and $\mathrm{B}$ cells for 18 hours $(\mathbf{G}) \pm \mathrm{SEM}$. 
Fold-expression of one represents spontaneous apoptosis in culture medium (respectively 20\%, 12\%, and 8\%). (E) Two-way repeated measures ANOVA test ${ }^{*} P<0.01$, ${ }^{* *} P<0.001$. (F and $\mathbf{G}$ ) Friedman and Dunn's post-test, ${ }^{*} P<0.05$. (H) Mitochondrial DiOC6(3) accumulation was analyzed on total splenocytes incubated with anti-CD45RC mAb, dexamethasone, or isotype control mAb for $1 \mathrm{~h}$ to $18 \mathrm{~h}$ and stained for TCR and DAPI. Results are expressed as percentage of DiOC6(3)- cells among DAPI ${ }^{-}$T cells \pm SEM. Two-way repeated measures ANOVA test, ${ }^{* *} P<0.01,{ }^{* * *} P<0.001,{ }^{* * *} P<0.0001$.

accumulation of DiOC6(3) following incubation of the cells with anti-CD45RC mAb or dexamethasone in a time-dependent manner, in contrast with isotype control $\mathrm{mAb}$ (Figure $3 \mathrm{H}$ and Supplemental Figure $4 \mathrm{D})$, indicating that anti-CD45RC mAb trigger $\mathrm{CD} 45 \mathrm{RC}^{+} \mathrm{T}$ cell apoptosis through the intrinsic pathway.

Taken together, these data demonstrate that anti-CD45RC mAb treatment resulted in specific temporary and rapid death induction of $\mathrm{CD} 45 \mathrm{RC}^{\text {high }} \mathrm{T}$ cells through intrinsic cell signaling, while not only preserving $\mathrm{CD} 4^{+}$and $\mathrm{CD} 8^{+} \mathrm{CD} 45 \mathrm{RC}^{\text {low } /-}$ Tregs, but also increasing their numbers.

Transient anti-CD $45 R C \mathrm{mAb}$ treatment results in long-term donor-specific dominant tolerance mediated by transcriptionally modified $C D 8^{+}$and $C D 4^{+} C D 45 R C^{\text {low } /-}$ Tregs. We then examined whether tolerance establishment by short-term anti-CD45RC mAb treatment was effectively due to induction of potent suppressive regulatory cells.

We analyzed ex vivo suppressive capacities of Treg subsets, as previously described (22) (Figure 4, $\mathrm{A}$ and $\mathrm{B})$. $\mathrm{CD} 45 \mathrm{RC}^{\text {low/ }}-\mathrm{CD} 4^{+}$and $\mathrm{CD} 8^{+} \mathrm{T}$ cells from day 120 tolerant rats were analyzed for their in vitro suppressive capacity on syngeneic $\mathrm{CD} 4^{+} \mathrm{CD} 25^{-}$Teff activated by donor $\mathrm{pDCs}$. In the presence of $\mathrm{CD} 8{ }^{+} \mathrm{CD} 45 \mathrm{RC}^{\text {low } /-}$ Tregs from tolerant anti-CD45RC-treated recipients, we observed a significantly increased inhibition of the proliferation of $\mathrm{CD} 4^{+} \mathrm{CD} 25^{-} \mathrm{T}$ effector cells in a dose-dependent manner until at least an effector/suppressor ratio of 16:1 compared with naive cells (Figure 4A and Supplemental Figure 5). Although not significant, we also observed a trend for increased suppressive function of the $\mathrm{CD} 4{ }^{+} \mathrm{CD} 45 \mathrm{RC}^{\text {low/ }}-\mathrm{T}$ cells from tolerant anti-CD45RC-treated recipients compared with naive cells (Figure 4B and Supplemental Figure 5).

We next performed adoptive cell transfer of splenocytes or subpopulations from tolerant recipients (>120 days) into secondary cardiac grafted recipients (Figure 4C). Adoptive cell transfer of total splenocytes from anti-CD45RC-treated animals resulted in indefinite allograft survival (>120 days) in $86 \%$ of the recipients compared with recipients transferred with naive splenocytes or untreated recipients (median survival time $=7$ days both) (Figure 4D). In these recipients, we also observed complete absence of antidonor $\operatorname{IgG},-\operatorname{IgG} 1,-\operatorname{IgG} 2 \mathrm{a}$, and $-\operatorname{IgG} 2 \mathrm{~b}$ antibodies compared with untreated rats that had rejected their grafts (data not shown). In order to assess antigen specificity of sustained Tregs, we performed adoptive cell transfer of splenocytes from anti-CD45RC-treated animals into recipients grafted with a third-party heart and observed rapid allograft rejection (mean survival time $[\mathrm{MST}]=8$ days), demonstrating that tolerance induction was donor specific. We further assessed the subpopulation responsible for tolerance induction (Figure 4E). While we observed no significant prolongation of allograft survival in recipients adoptively transferred with B cells from anti-CD45RC-treated animals compared with B cells from naive rats (MST = 32 days vs. 29 days, respectively), we obtained indefinite allograft survival in $75 \%$ and $66.6 \%$ of recipients transferred with, respectively, $\mathrm{CD} 4^{+} \mathrm{CD} 45 \mathrm{RC} \mathrm{C}^{\text {low } /-} \mathrm{T}$ cells or $\mathrm{CD} 8^{+} \mathrm{CD} 45 \mathrm{RC} \mathrm{C}^{\text {low } /-}$ Tregs from anti-CD45RC-treated animals compared with naive rats (MST $=9$ days and 10 days, respectively). This demonstrates that transient $\mathrm{CD} 45 \mathrm{RC}$-specific $\mathrm{mAb}$ treatment induced both $\mathrm{CD} 4^{+}$and $\mathrm{CD} 8^{+}$Tregs with stronger suppressive capacity compared with naive Tregs, while it had no effect on B cells.

To demonstrate that the short-term anti-CD45RC mAb treatment led to sustained transcriptional modification of the Tregs (Figure 5 and Supplemental Figure 6), we performed 3' digital expression RNA-Seq (DGE-Seq) on four groups of samples: naive $\mathrm{CD} 4{ }^{+} \mathrm{CD} 45 \mathrm{RC}^{\text {low/-, }}$, anti-CD45RC-treated $\mathrm{CD} 4{ }^{+} \mathrm{CD} 45 \mathrm{RC} \mathrm{C}^{\text {low/ }}$, naive $\mathrm{CD} 8{ }^{+} \mathrm{CD} 45 \mathrm{RC}^{\text {low } /}$, anti-CD45RC-treated $\mathrm{CD} 8{ }^{+} \mathrm{CD} 45 \mathrm{RC}^{\text {low/- }}$ (European Nucleotide Archive [ENA] study accession number PRJEB18559). One hundred and seventy-nine genes were significantly upregulated and 274 were downregulated in anti-CD45RC-treated vs. naive $\mathrm{CD} 4^{+} \mathrm{CD} 45 \mathrm{RC} \mathrm{C}^{\text {low/- }}$ Tregs, and 362 genes were upregulated and 594 were downregulated in anti-CD45RC-treated vs. naive $\mathrm{CD} 8^{+} \mathrm{CD} 45 \mathrm{RC} \mathrm{C}^{\text {low } /-}$ Tregs (Figure 5A and Supplemental Figure 6). Strikingly, only 22 genes overlapped between upregulated genes in anti-CD45RC-treated $\mathrm{CD} 4^{+}$and $\mathrm{CD} 8^{+} \mathrm{CD} 45 \mathrm{RC}^{\text {low } /-}$ Tregs when compared with naive $\mathrm{CD} 4^{+}$and $\mathrm{CD} 8^{+}$ CD45RC $\mathrm{Cow}^{\text {low }}$ Tregs, respectively (Figure $5 \mathrm{~A}$ ). This suggests that, despite an equal ability for $\mathrm{CD} 4^{+}$and $\mathrm{CD} 8^{+}$ Tregs to induce tolerance, their immune memory set in place during anti-CD $45 \mathrm{RC}$ treatment is mediated by diverse signaling pathways/molecular regulators. Among the common upregulated genes detected in Tregs from anti-CD45RC-treated tolerant rats, Illb, Illr2, and Ceacam4 genes, whose expressions are related to 
A

ت Naive $C D 8^{+}$CD45RC low- $T$ cells, $n=4$

- Anti-CD45RC treated $\mathrm{CD}^{+}{ }^{+}$CD45RC ${ }^{\text {low- }}$ $T$ cells, $n=4$

호웡

125

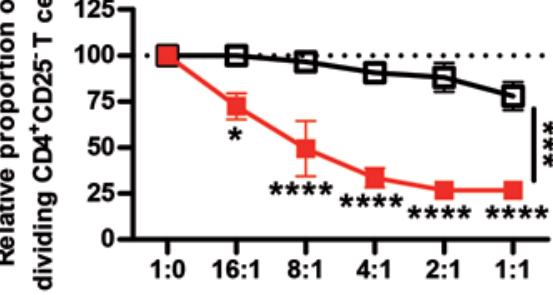

C

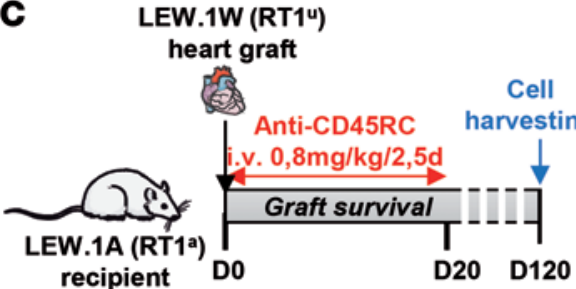

D

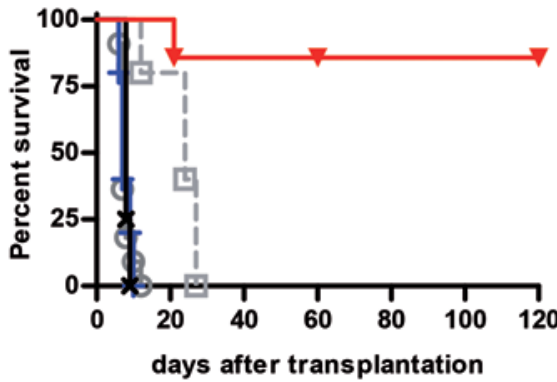

E

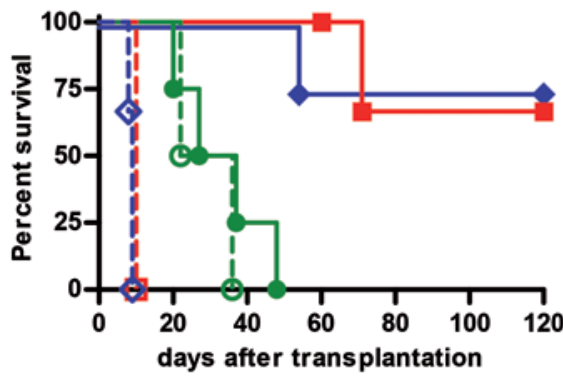

B

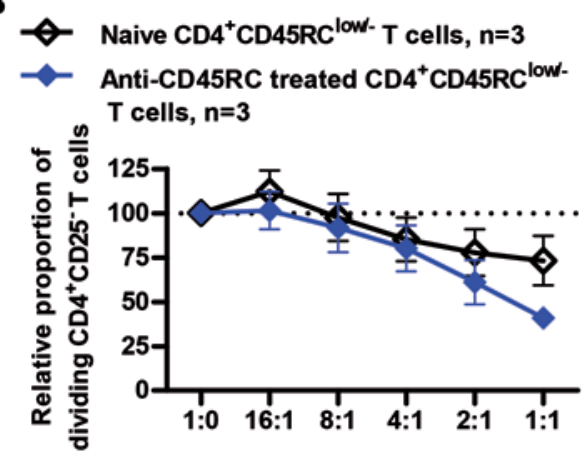

LEW.1W (RT14) or BN (RT1" heart graft
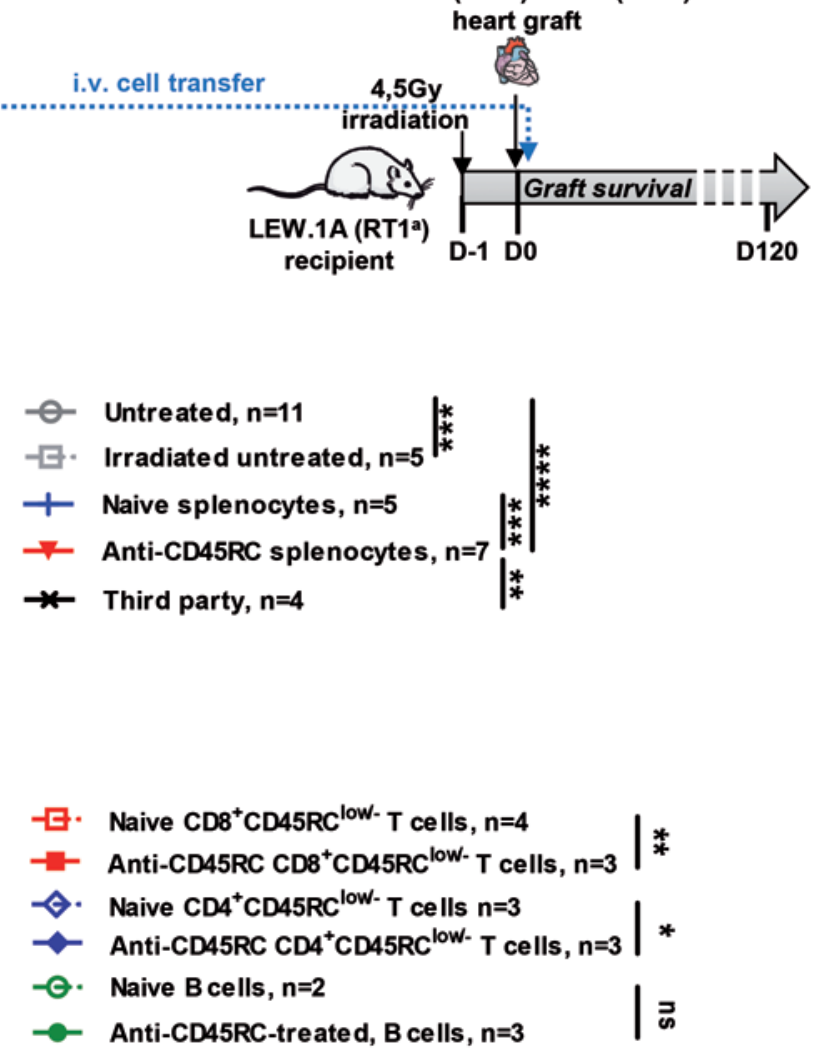

Figure 4. Transient anti-CD45RC mAb treatment results in long-term dominant tolerance mediated by CD8 ${ }^{+}$and $C D 4^{+}$CD45RClow/- Tregs. (A and $\left.B\right)$ CFSE-labeled LEW.1A dividing CD4+CD25- T cells stimulated with donor LEW.1W pDCs were analyzed after 6 days of culture in the absence or presence of LEW.1A naive or day-120 anti-CD45RC-treated CD8+CD45RC low/- $^{+}(\mathbf{A}, n=4)$ or CD4+CD45RC ${ }^{\text {low/- }}(\mathbf{B}, n=3)$ Tregs in a range of effector/suppressor ratio. The proportion of dividing $\mathrm{CD} 4{ }^{+} \mathrm{CD} 25^{-} \mathrm{T}$ cells in the control proliferation condition with pDCs only represented about $70 \%$ of the cells at day 6 and was given the value 100 in each experiment. Two-way repeated measures ANOVA test. Bonferroni post-test. ${ }^{*} P<0.05,{ }^{* * *} P<0.001,{ }^{* * *} P<0.0001$. (C) Schematic representation of adoptive cell transfer from day-120 tolerant transplanted-treated recipients to newly grafted irradiated recipients. (D) LEW.1A recipients were sublethally irradiated (4.5 Gy) at day -1 and received heart allografts from donor type (LEW.1W) or third-party type (BN, $n=4)$ and i.v. injection of splenocytes from long surviving anti-CD45RC-treated recipients $(n=7)$ or from naive rats $(n=5)$. Nonirradiated nontreated recipients (untreated, $n=11)$ and irradiated nontreated $(n=5)$ recipients were used as controls. Log rank test (Mantel Cox), ${ }^{* *} P<0.01,{ }^{* * *} P<0.001,{ }^{* * *} P<0.0001$. (E) LEW.1A recipients were sublethally irradiated (4.5 Gy) at day -1 and received heart allografts and i.v. injections of sorted subpopulations from long surviving anti-CD45RC-treated recipients or from naive rats $(n=2-4)$. Graft survival was monitored by abdominal palpation. Log rank test (Mantel Cox), ${ }^{*} P<0.05,{ }^{* *} P<0.01$.

IL-10 production by Tregs (26); MHC class 2-related genes such as Cd74 and Rt1-da; and tolerance-related genes such as Tmem176b, Hopx, Lgmn, and S100a9 are involved in induced Treg function and maintenance (27-29) (Figure 5, A-C). We also observed the upregulation of genes that can be associated to Tregs such as Il2, Il2rb, Illorb, Fgl2, Ccr6, and Cd7 (24, 30, 31). Runx2 and Nr4a3 are involved in the thymic differentiation of Tregs, the expression of Foxp3, and immune homeostasis. To find new regulators, we looked at transcription 
A

\begin{tabular}{l|c} 
A & Up regulation \\
Oे & Down regulation
\end{tabular}

Up regulation
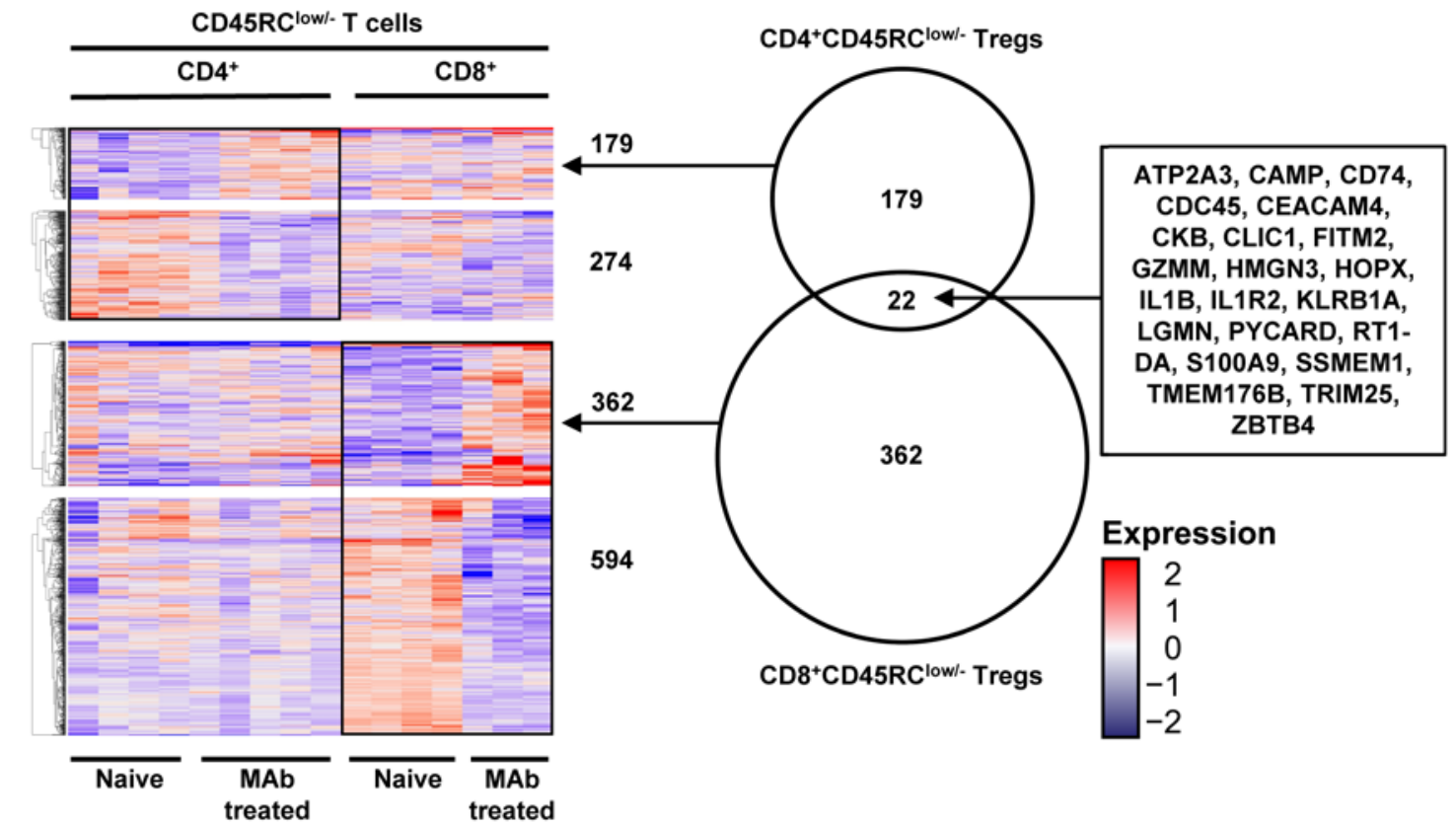

362

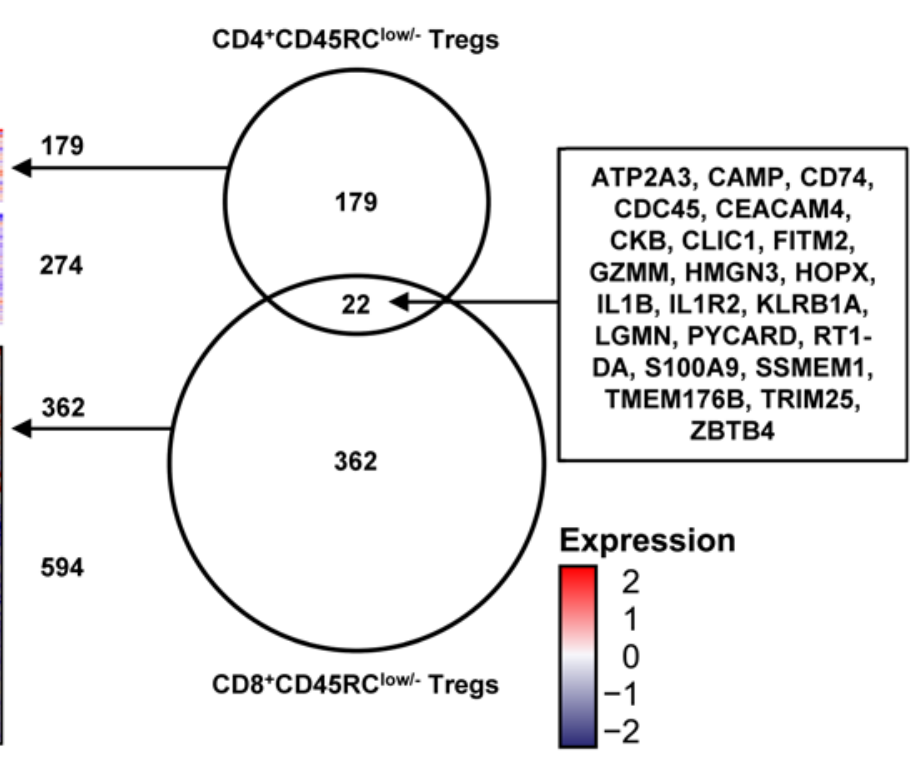

594

B

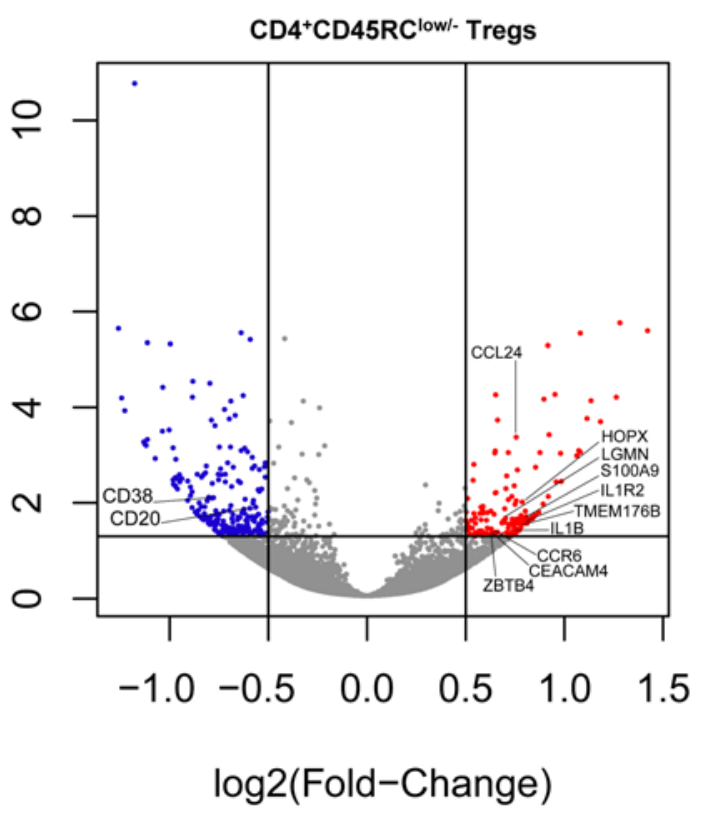

C

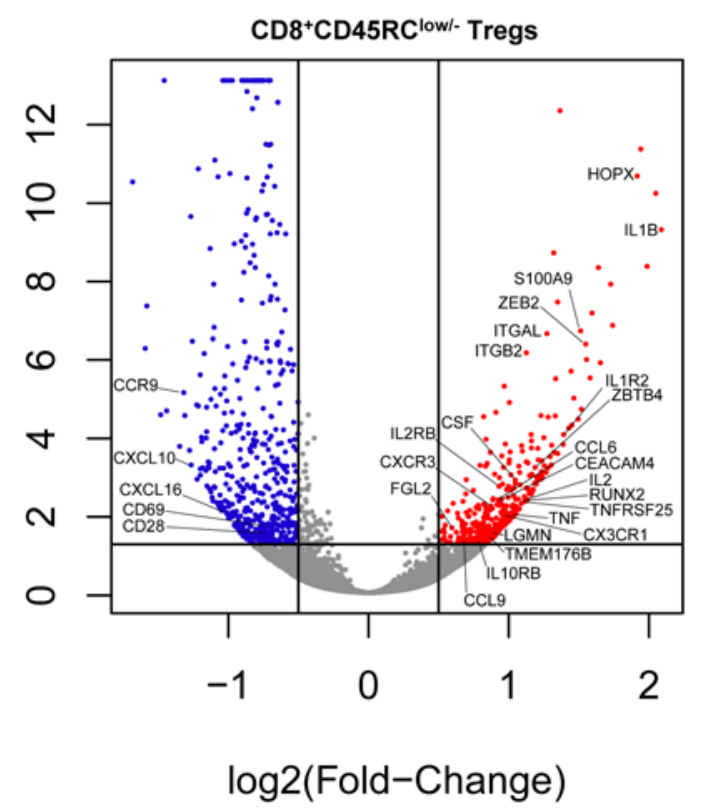

Figure 5. Transient anti-CD45RC mAb treatment results in sustained transcriptional changes in long-term CD8 ${ }^{+}$and CD4+ CD45RC'low/- Tregs. (A) $3^{\prime} \mathrm{CGE}$ RNA-seq analysis was performed on CD4 ${ }^{+}$and $C D 8^{+}$CD45RClow/- Tregs from anti-CD45RC mAb treated vs. untreated rats. Expression levels of differentially expressed genes are presented as a heatmap; low expression levels are in blue, mean expression levels are in white, and high expression levels are in red. Venn diagrams highlight unique and shared genes upregulated by $\mathrm{CD} 4^{+}$and $\mathrm{CD} 8^{+} \mathrm{CD} 45 \mathrm{R} \mathrm{C}^{\text {low/- }}$ Tregs from anti-CD45RC mAb treated vs. untreated rats. (B and C) Volcano plot representation of differentially expressed genes between treated and untreated CD4+ Tregs (B) or CD8 $8^{+}$Tregs (C). The $q$ value (adjusted $P$ value) cut-off is 0.05 and the $\log _{2}$ fold-change cutoff value is \pm 0.5 . Red dots, genes overexpressed in Tregs; blue dots, genes downregulated in Tregs.

factors and related genes in the genes identified as associated with anti-CD45RC tolerance and found overexpression of Zbtb4, a transcriptional repressor, and Zeb2, a transcription factor, that play a role in TGF $\beta$ signaling pathway. We found the upregulation on $\mathrm{CD} 8^{+} \mathrm{CD} 45 \mathrm{R} \mathrm{C}^{\text {low } /-} \mathrm{T}$ cells from anti-CD45RC-treated tolerant rats of genes involved in immune function; the genes included Itgal and Itgb2, which combine to control Treg homing (32); Tnfrs 25 , which is described as highly expressed by $\mathrm{CD} 4^{+}$Tregs and a therapeutic target to promote Treg expansion (33,34); and Tnf, $C x c r 3$, or $C c l 9$ (Figure 5C). Finally, we observed the downregulation of activation markers such as $C d 38, C d 69, C d 28$, and $C d 40 l$ and the downregulation of chemokine receptor $C c r 9$ and chemokine $\mathrm{Cxcl10}$ and $\mathrm{Cxcl16}$. 
$\mathrm{A}$
$\mathrm{CD}^{+}$

T cells
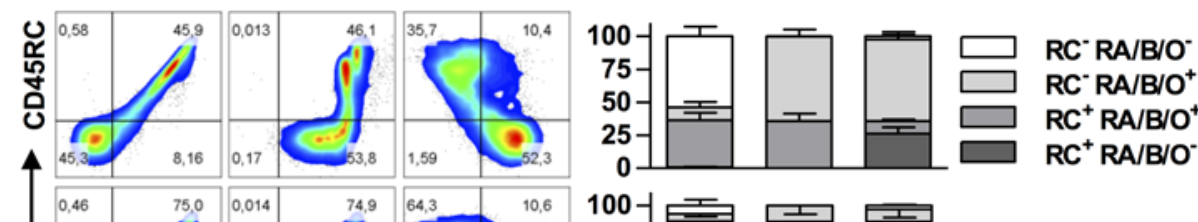

CD8 ${ }^{+}$

T cells
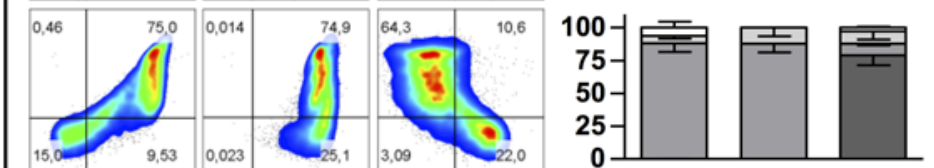

B cells
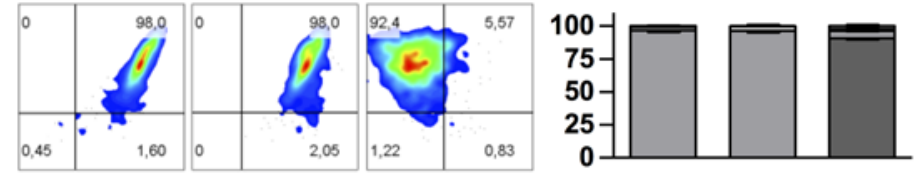

NKT cells
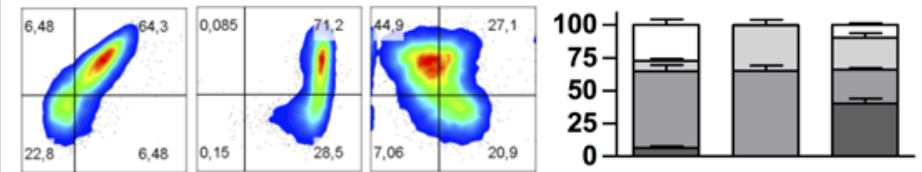

NK cells
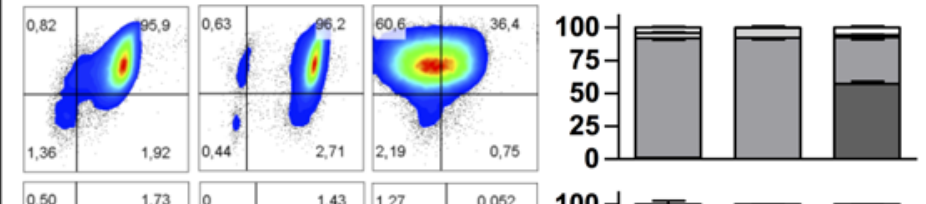

$\mathrm{CD}^{+} 4^{+}$

monocytes
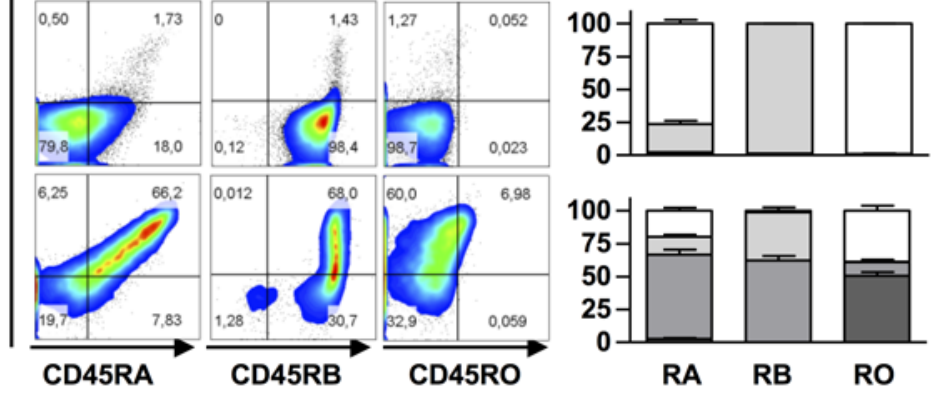

CD16 ${ }^{+}$ monocytes

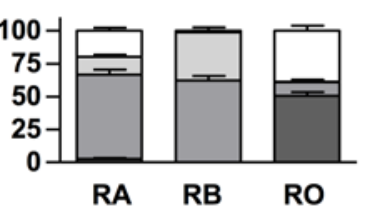

Isotype Abs

- Anti-CD45 Abs
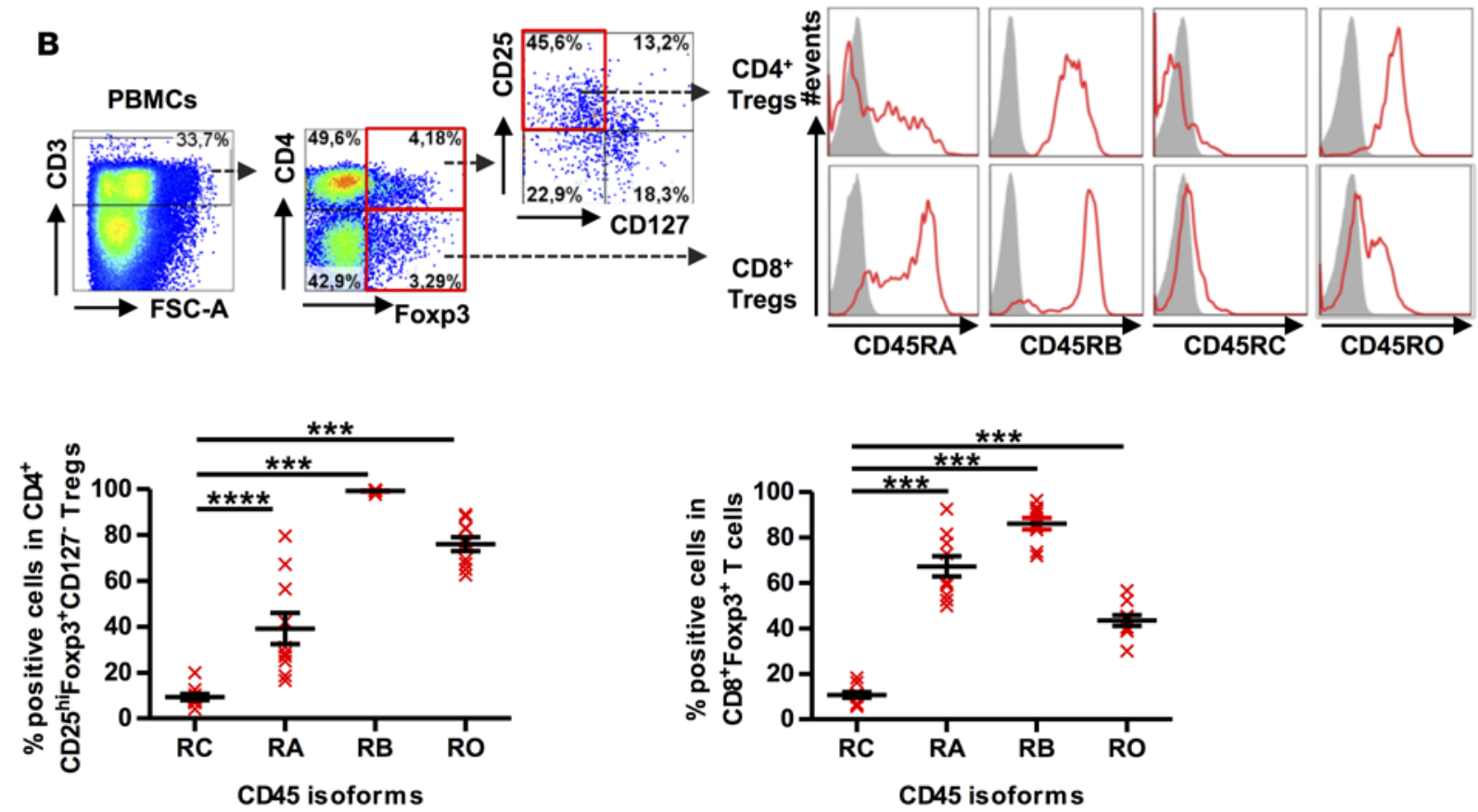
Figure 6. CD45RC isoform identifies a unique subset of lymphocytes and is the only CD45-isoform not expressed by human Foxp3 $3^{+}$Tregs. (A) Analysis of CD45 isoform expression on human peripheral blood PBMCs. CD4 ${ }^{+}$and CD8 ${ }^{+} T$ cells, B cells, NK cells, NKT cells, and CD14+ or CD16 ${ }^{+}$monocytes were analyzed for CD45RC marker coexpression with CD45RA, CD45RB, and CD45R0 markers by flow cytometry. Left: A representative experiment of 10 individuals. Right: Mean expression \pm SEM of CD45RA, CD45RB, or CD45RO in CD45RC+ or CD45RC- in each cell population of 10 different individuals. (B) Analysis of CD45 isoform expression by CD4+ and CD8 ${ }^{+}$Foxp3 $^{+}$Tregs from human peripheral blood PBMCs. CD4+CD25+CD127-Foxp3 ${ }^{+}$and $\mathrm{CD}^{+}{ }^{+}$Foxp3 ${ }^{+} \mathrm{T}^{+}$cells were analyzed for CD45RA, -RB, -RC, and -RO marker expression by flow cytometry. Top panel is a representative experiment of 10 individuals. Bottom panel represents $\%$ of positive cells among Tregs \pm SEM. Mann-Whitney $U$ Test, ${ }^{* *} P<0.001,{ }^{* * *} P<0.0001$.

Altogether, our data demonstrate that transient targeting of CD45RC resulted in induction and maintenance of antigen-specific $\mathrm{CD} 4^{+}$and $\mathrm{CD} 8^{+} \mathrm{CD} 45 \mathrm{RC}^{\text {low/- }}$ Tregs of increased suppressive activity on a per-cell basis. Our transcriptomic analysis reveals a distinct transcriptomic signature between tolerogenic $\mathrm{CD} 4^{+}$and $\mathrm{CD}^{+}$cells with upregulation of a common specific pattern of Treg-associated genes.

CD45 isoforms identify unique subsets of lymphocytes, highlighting CD45RC as the only isoform not expressed by human $\mathrm{CD}^{+}$and $C D 8^{+} \mathrm{Foxp}^{+}$Tregs. As a first step in the assessment of the therapeutic potential of an antiCD45RC treatment in humans to induce tolerance, we analyzed the expression of CD45RC on PBMCs and in combination with CD45RA, CD45RB, and CD45RO (Figure 6A and Supplemental Figure 7A). We observed complex and nonredundant CD45 isoform expression at the surface of T, B, NK, and NKT cells and monocytes. In humans, as in the rats, CD45RC is highly expressed by B cells and T cells (18), but we also observed a strong expression by NK and NKT cells, as well as CD16 ${ }^{+}$monocytes, but no expression by $\mathrm{CD}_{14}{ }^{+}$monocytes (Figure 6A). We observed a correlation of CD45RA and CD45RC expression on $\mathrm{CD}^{+} \mathrm{T}$ cells and $\mathrm{CD} 16^{+}$monocytes; in contrast, there are $\mathrm{CD} 45 \mathrm{RC}^{\text {low/- }}$ cells that displayed a high expression of CD45RA in $\mathrm{CD}^{+} \mathrm{T}$ cells and $\mathrm{B}$ cells or a negative expression of CD45RA in NKT cells and NK cells. More precisely, CD45RClow/- $\mathrm{CD}^{+} \mathrm{T}$ cells had a low proportion of $\mathrm{CD}^{+} 5 \mathrm{RA}^{+}$cells, and the large majority was $\mathrm{CD} 45 \mathrm{RO}^{+}$; however, in $\mathrm{CD} 45 \mathrm{RC}^{\text {low/- }} \mathrm{CD}^{+} \mathrm{T}$ cells, there are $\mathrm{CD} 45 \mathrm{RA}^{+/ \text {int/neg }}$ cells, and the large majority was $\mathrm{CD}^{2} 5 \mathrm{RO}^{-}$. Strikingly, $\mathrm{T}$ cells were all positive for $\mathrm{CD} 45 \mathrm{RB}$, suggesting that targeting the isoforms CD45RB or CD45RO would include at least CD8 ${ }^{+}$Tregs, while targeting CD45RC would spare them. In addition, CD45RC $\mathrm{C}^{\text {high }} \mathrm{T}$ cells were positive for CD45RA and CD45RB and negative for CD45RO, suggesting that targeting isoform CD45RC would specifically eliminate naive/TEMRA/effector cells and preserve memory $\mathrm{T}$ cells and Tregs. CD19+ $\mathrm{B}$ cells and NK cells were all positive for CD45RA, CD45RB, and CD45RC and negative for CD45RO. Furthermore, CD14+ monocytes were all positive for CD45RB but negative for the other isoforms. Finally, NKT cells and $\mathrm{CD}_{1} 6^{+}$monocytes were all $\mathrm{CD} 45 \mathrm{RB}^{+}$and mainly CD45RO-, but they expressed differential levels of CD45RA and CD45RC.

Analysis of CD45 isoform expression by CD4 ${ }^{+} \mathrm{CD} 25^{+} \mathrm{CD} 127^{-} \mathrm{Foxp}^{+}$Tregs and $\mathrm{CD} 8^{+} \mathrm{Foxp}^{+}$Tregs revealed very low levels of expression of the CD45RC isoforms but a mostly high expression of CD45RA, $\mathrm{CD} 45 \mathrm{RB}$, and/or CD45RO (Figure 6B). The CD45RB isoform was the most significantly expressed isoform by both $\mathrm{CD}^{+} \mathrm{CD} 25^{+} \mathrm{CD} 127^{-} \mathrm{Foxp}^{+}$and $\mathrm{CD}^{+} \mathrm{Foxp}^{+}$Tregs. Interestingly, we observed that a $16 \%$ of $\mathrm{CD}^{+} \mathrm{CD}^{+} 5^{+} \mathrm{CD} 127^{-} \mathrm{Foxp}^{+}$and $32 \%$ of $\mathrm{CD}^{+} \mathrm{Foxp}^{+}$Tregs coexpressed CD45RA and CD45RO, while these markers are mutually exclusive in Foxp3 $3^{-} \mathrm{CD} 4^{+}$or $\mathrm{CD}^{+} \mathrm{T}$ cells (Supplemental Figure 7B).

Altogether, these results confirm that CD45RC is the only isoform at the interface of effector/regulatory subsets and could lead to an efficient therapeutic strategy sparing Tregs.

Anti-human CD45RC treatment reduces lethality in a model of acute GVHD in humanized mice. Finally, to provide proof of concept using human cells, we tested whether anti-human CD45RC mAb (clone MT2, mouse IgG1) would induce cell death of human T cells in vitro and could prevent the development of acute GVHD by human cells (Figure 7).

We observed that incubation of anti-human CD45RC mAb, but not isotype control mAb, with PBMCs from healthy individuals significantly induced apoptosis of $\mathrm{T}$ cells in a time-dependent manner, similarly to ATG, which induces cell death (Figure 7A and Supplemental Figure 8A). In contrast, we did not observe cell death of non-T cells following incubation with anti-human CD45RC mAb (Figure 7B).

We next used a model in which NSG recipient mice received human PBMCs and analyzed weight loss and lethality as a consequence of xenogeneic GVHD. Anti-human CD45RC mAb was used to eliminate $\mathrm{CD} 45 \mathrm{RC}^{\text {high }}$ cells from human PBMCs prior to administration (cells were sorted ex vivo based on CD45RClow/- Treg expression) or was injected directly in vivo following unmanipulated PBMC administration (Figure 7, C and D; Supplemental Figure 8, B-F; and Supplemental Figure 9). Depletion of CD45RChigh cells from PBMCs (Supplemental Figure $8 \mathrm{~B}$ ) reduced the proportion of $\mathrm{CD}^{\text {h }} 6^{+}$monocytes and of NK cells (Supplemental Figure 8C). We observed significantly more CD45RO ${ }^{+}$cells and fewer 
A

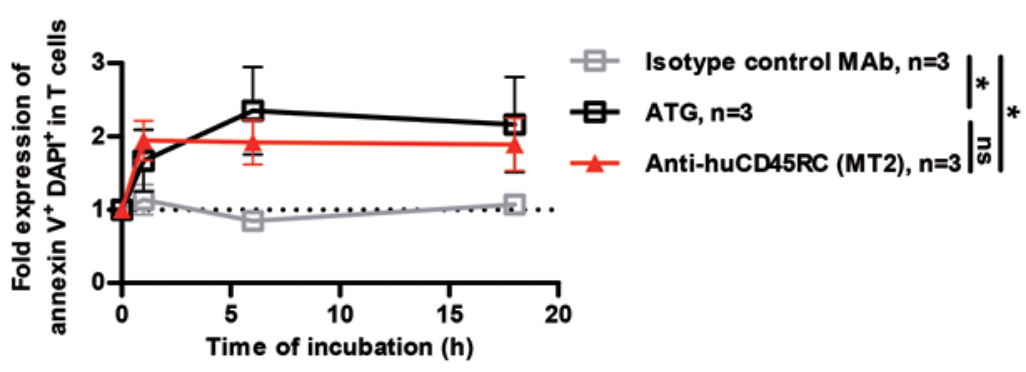

C

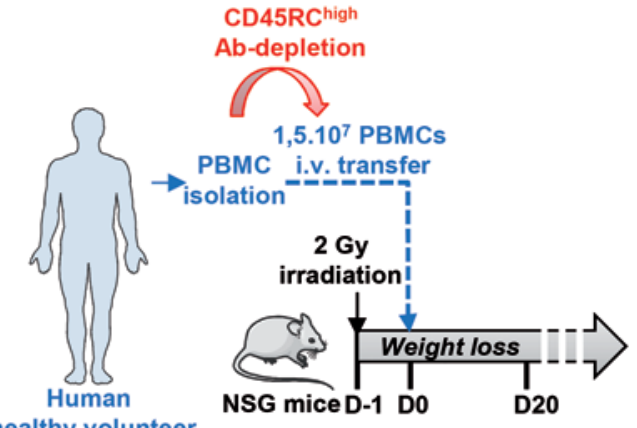
healthy volunteer
NSG mice D-1 Do
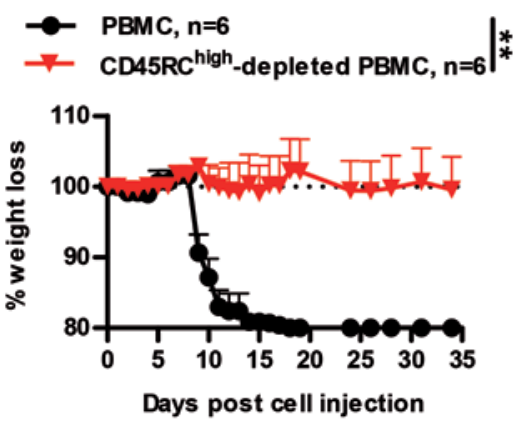

B

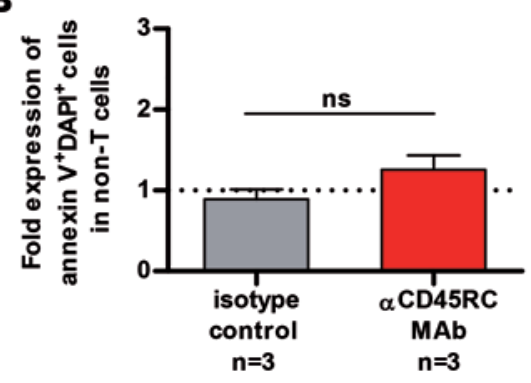

D
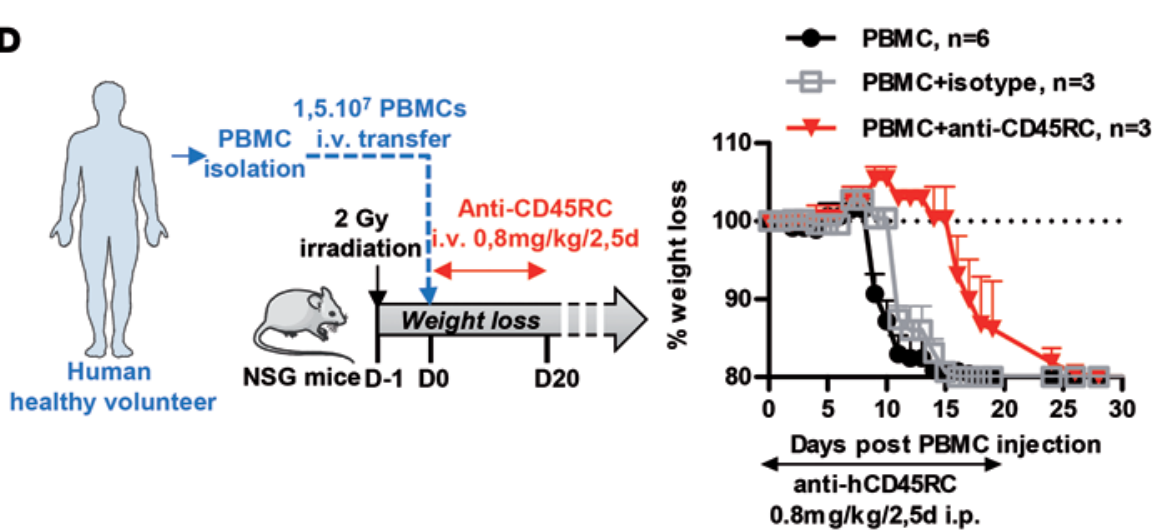

Figure 7. Anti-human CD45RC treatment reduces lethality in a model of GVHD in humanized mice. Apoptosis was analyzed on human PBMCs incubated with anti-human CD45RC mAb, ATG, or an isotypic control and stained by flow cytometry with annexin V and DAPI. Results are expressed as relative proportion of positive cells among T cells for 1 to $18 \mathrm{~h}(\mathbf{A})$ and non-T cells for 18 hours (B) \pm SEM. (A) Two-way repeated measures ANOVA test, ${ }^{*} P<0.05$. (B) Wilcoxon matched-pairs signed rank test. Fold-expression of one represents spontaneous apoptosis in culture medium (10\%). (C) PBMCs were depleted in CD45RC ${ }^{\text {high }}$ cells and then transferred in NSG mice as compared with total PBMCs to induce GVHD occurrence characterized by $20 \%$ weight loss ( $n=6$ for each group). Results are expressed in percentage of weight loss (left) and mice survival (right). (D) NSG mice transferred with total PBMCs were treated with either anti-human CD45RC mAb (MT2, $n=3)$ or isotypic control $(n=3)$ or untreated $(n=6)$. Results are expressed in percentage of weight loss (left) and mice survival (right). Two-way repeated measures ANOVA and Log rank (Mantel Cox) tests, ${ }^{*} P<0.05,{ }^{* *} P<0.01,{ }^{* *} P<0.001$.

CD45RA ${ }^{+}$cells among $\mathrm{CD} 4^{+}$and $\mathrm{CD} 8^{+} \mathrm{T}$ cells, and observed no impact on CD45RB (Supplemental Figure 8D). Interestingly, we observed that recipients that received PBMCs that were depleted ex vivo of $\mathrm{CD} 45 \mathrm{RC}^{+}$cells were almost completely protected from weight loss and lethality by GVHD, in contrast to recipients that received unmanipulated PBMCs ( $85.7 \%$ long-term survival vs. MST $=11$ days, respectively) (Figure 7C). Similarly, administration in vivo of anti-human CD45RC mAb $(0.8 \mathrm{mg} / \mathrm{kg}$ i.p.) resulted in a significant delay of weight loss and GVHD occurrence compared with the recipients administered with control irrelevant $\mathrm{mAb}$ (MST $=19$ days vs. 15 days, respectively) (Figure 7D). In vivo depletion with antihuman $\mathrm{CD} 45 \mathrm{RC} \mathrm{mAb}$ resulted in a stronger decrease of $\mathrm{CD} 45 \mathrm{RC} \mathrm{C}^{\text {high }} \mathrm{CD} 4^{+}$and $\mathrm{CD} 8^{+} \mathrm{T}$ cells from day 7 to day 21 (Supplemental Figure 9A) and, in contrast, an increase of $\mathrm{CD} 4^{+} \mathrm{CD} 45 \mathrm{RC} \mathrm{C}^{\text {low/- }} \mathrm{T}$ cells (Supplemental Figure 9B) compared with controls. We observed no significant differences on other immune cell populations (Supplemental Figure 9C). Importantly, in both groups, mice that did not develop any GVHD were 


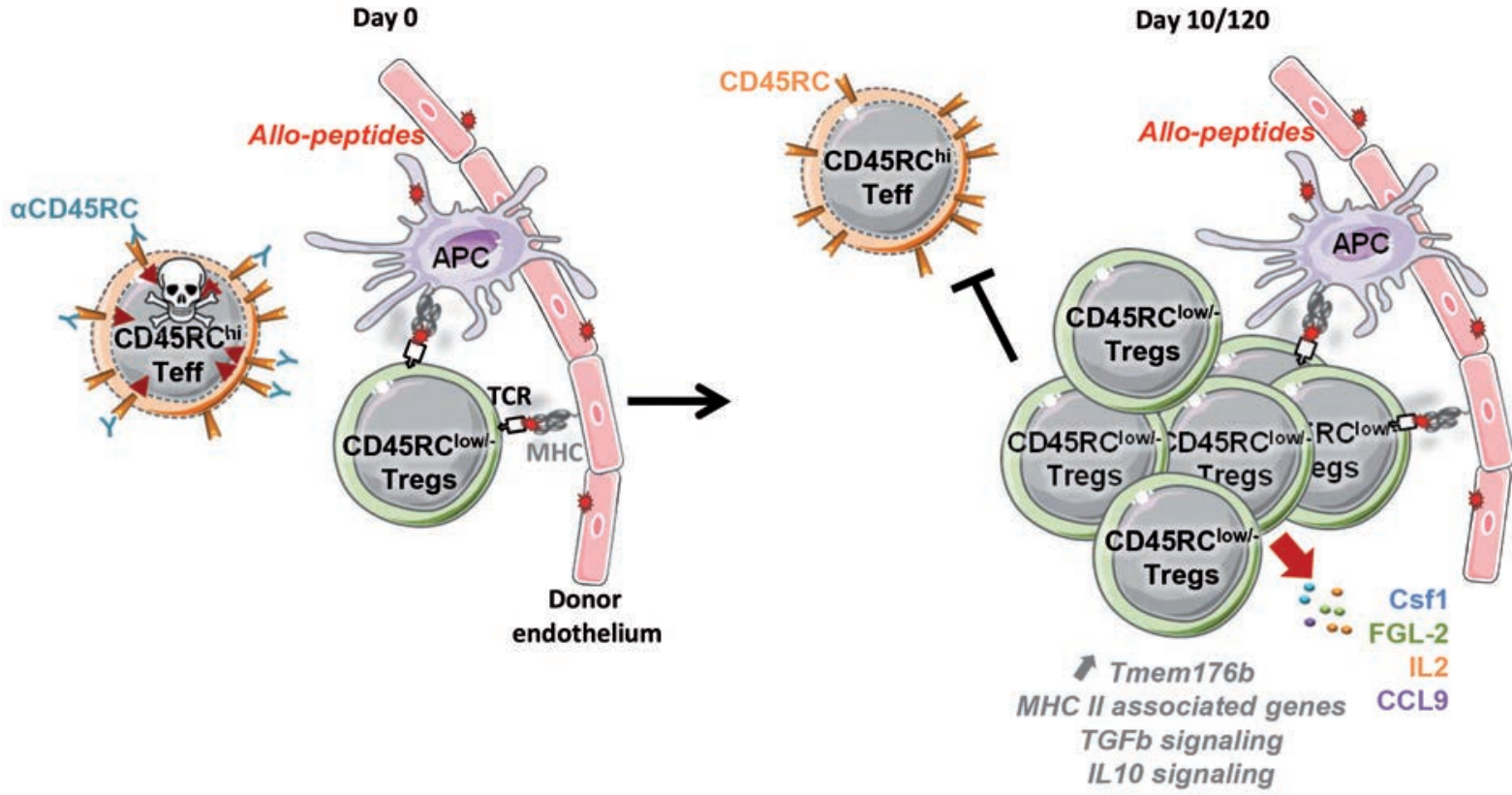

Figure 8. Mode of action of anti-CD45RC mAb treatment in a model of organ transplantation. Antibodies directed to CD45RC surface expression - a molecule present on the surface of naive and TEMRA effector T cells (Teff) - bind and induce apoptosis-mediated T cell death, while preserving CD4 ${ }^{+}$and CD8 ${ }^{+}$ Tregs. In absence of Teff, CD45RClow/- Tregs recognize allopeptides derived from the donor and presented by the antigen-presenting cell (APC; indirect presentation pathway) or directly recognize donor endothelium MHC molecules (direct presentation pathway) and undergo homeostatic proliferation. During this homeostatic proliferation, CD45RC ${ }^{\text {low/- }}$ Tregs modify their transcriptional profile, and following arrest of anti-CD45RC mAb treatment, CD45RC ${ }^{\text {low/- }}$ Tregs maintain a state of tolerance indefinitely.

engrafted with human PBMCs proportionally to $\mathrm{CD} 45 \mathrm{RC}^{+/-}$composition in PBMCs (Supplemental Figure 8, E and F, and Supplemental Figure 9, D and E). Altogether, these results show that anti-CD45RC therapy has the potential to blunt human immune responses.

\section{Discussion}

In this paper, we show that sustained antigen-specific $\mathrm{CD} 4^{+}$and $\mathrm{CD} 8^{+} \mathrm{CD} 45 \mathrm{RC} \mathrm{C}^{\text {low } /-}$ Tregs are key actors of immune tolerance induced by CD45RC-specific antibody treatment (Figure 8). We demonstrated that transient anti-CD45RC $\mathrm{mAb}$ triggers rapid $\mathrm{CD} 45 \mathrm{RC}^{+} \mathrm{T}$ cell apoptosis, while preserving memory immunity. To date, there is no therapy with these properties in clinical organ transplantation (35). Clinical protocols applying polyclonal or antigen-specific $\mathrm{CD} 4^{+}$Treg cell therapy in transplantation are underway and hold promise, but results are not yet available (36). In the last years, we have investigated the properties of a population of $\mathrm{CD} 8^{+}$Tregs that arise in a model of cardiac allograft tolerance following blocking of CD40-CD40L interactions $(18,20,21,23,24,37-39)$ and are characterized by the low expression or absence of the CD45RC marker, which is one of the less known and studied alternative splice variants of the CD45 molecule.

We demonstrate here that humans CD45 isoforms identify distinct subsets of cells and are not redundant. We show the differential expression of these variants by human $\mathrm{CD} 45 \mathrm{R} \mathrm{C}^{\text {low } /-} \mathrm{T}$ cells, with heterogeneous expression for CD45RA and CD45RO, while most were positive for CD45RB. Importantly, CD45RC is not expressed by $\mathrm{CD} 4^{+}$and $\mathrm{CD} 8^{+}$Foxp $3^{+}$Tregs, while CD45RA, CD45RB, and CD45RO are expressed by $40 \%-100 \%$ of them. This is the first evidence of such understanding of human Tregs. Therefore, whereas anti-CD45RA, - RB, or -RO treatment would result in depletion of most or at least a large fraction of Tregs, we could preserve them with an anti-CD45RC treatment. Thus, we can speculate that the effect of anti-CD45RC mAb would not be recapitulated with anti-CD45RA, anti-CD45RB, or anti-CD45RO $\mathrm{mAb}$. Unfortunately, there are no $\mathrm{mAb}$ available against rat $\mathrm{CD} 45 \mathrm{RA}, \mathrm{CD} 45 \mathrm{RB}$, or CD45RO; there is only one isoform against CD45RA, but it is specific of B cells. For several years, we and others acquired solid knowledge on the function of CD45RC-expressing cells based mostly on our own studies performed in rat models, probably because of a paucity of anti-CD $45 \mathrm{RC} \mathrm{mAb}$ in humans and mice. Indeed, it has been 
shown phenotypically and functionally (by cytokine secretion) that rat $\mathrm{CD} 45 \mathrm{R} \mathrm{C}^{\text {high }} \mathrm{T}$ cells resemble $\mathrm{Th} 1$ effector cells capable to induce graft rejection and organ autoimmunity $(15,16)$, while CD45RClow/- $\mathrm{T}$ cells are similar to Th2 and regulatory cells able to inhibit allograft rejection, GVHD, and cell-mediated autoimmune diseases (17-19). We have intensively described, in a model of organ transplantation tolerance, induced $\mathrm{CD}^{+} \mathrm{CD} 45 \mathrm{RC}^{\text {low/- }}$ Tregs cells with potent suppressive capacity $(18,20,22,38)$. We showed that donor-specific $\mathrm{CD} 8{ }^{+} \mathrm{CD} 45 \mathrm{RC}^{\text {low } /-}$ Tregs, but not natural $\mathrm{CD} 8{ }^{+} \mathrm{CD} 45 \mathrm{RC} \mathrm{C}^{\text {low } /-}$ Tregs, transferred tolerance to naive cardiac transplant recipients. In addition, allograft survival was dependent on $\mathrm{CD} 8^{+} \mathrm{CD} 45 \mathrm{RC} \mathrm{C}^{\text {low/ }}$ Treg secretion of IFN $\gamma$ to enhance indoleamine 2,3-dioxygenase expression by DCs and graft endothelial cells (18). We also recently showed that the suppressive activity of the $\mathrm{CD} 8^{+} \mathrm{CD} 45 \mathrm{RC} \mathrm{Cow}^{\text {l- }}$ Tregs was mainly performed in the presence of pDCs (22), and that fibrinogen-like protein 2 (24), IL-34 (39), and recognition of a dominant MHC-II-derived donor peptide presented by recipient MHC-I (21) were involved in the suppression. Finally, we showed that $\mathrm{CD} 8{ }^{+} \mathrm{CD} 45 \mathrm{R} \mathrm{C}^{\text {low/- }}$ Tregs and $\mathrm{pDC}$ accumulated in allograft and spleen but not lymph nodes and that contact was necessary for suppression of $\mathrm{CD}^{+} \mathrm{T}$ cells (22). In humans, Saoudi and colleagues described that human $C D 45 R C^{\text {high }}$ and $C D 45 R C^{\text {low } /-} \mathrm{T}$ cells were able to secrete Th1 and Th2 cytokines, respectively, similarly to that observed in rats (10). In addition, the same group described a poor prognosis and a higher risk of acute rejection for kidney transplant patients exhibiting more than $54.7 \%$ of $\mathrm{CD}^{+} \mathrm{CD} 45 \mathrm{RC}^{\text {high }}$ cells before transplantation, suggesting that $\mathrm{CD} 45 \mathrm{RC}^{\text {high }}$ cells are important effectors of immune allograft rejection. Recently, we showed that human $\mathrm{CD} 8^{+} \mathrm{CD} 45 \mathrm{RC} \mathrm{C}^{\text {low }}$ Tregs were able to inhibit alloimmune responses in vitro through IL-34 secretion (39). These observations led to the hypothesis that transient anti-CD45RC mAb, which depletes CD45RC ${ }^{+}$cells, could induce not only transplant tolerance, but also favor $\mathrm{CD} 45 \mathrm{RC}^{\text {low/- }}$ Treg generation. Tolerance induction in two different alloincompatible rat strain combinations suggests that targeting the CD45RC molecule could be superior to anti-CD45RB mAb therapy, which resulted in a significant but only moderate increase of allograft survival in animal models, along with chronic rejection (40-46). Indeed, our results suggest that anti-CD45RB $\mathrm{mAb}$ could target all Foxp $3^{+} \mathrm{CD}^{+}$and $\mathrm{CD} 8^{+}$Tregs. The use of anti-CD45RA mAb could also eliminate a fraction of $\mathrm{Foxp}^{+} \mathrm{CD}^{+}$and $\mathrm{CD} 8^{+}$Tregs that express this marker $(47,48)$. A pilot study demonstrated the feasibility of depletion of naive T cells with magnetic CD45RA beads to avoid GVHD in patients (49). We suggest that prevention of GVHD in humans could also be obtained with anti-CD45RC treatment, as depletion of $\mathrm{CD}^{4} 5 \mathrm{RC}^{+}$cells resulted in total inhibition of GVHD in 5 of 6 recipients.

In addition, we observed that CD45RChigh $\mathrm{T}$ cells were positive for CD45RA and CD4RB and negative for CD45RO, suggesting that targeting the CD45RC isoform would more specifically eliminate naive and TEMRA cells but would spare memory $\mathrm{T}$ cells and thus preserve memory immunity. In recent years, it has been shown that $\mathrm{CD} 8^{+}$and $\mathrm{CD} 4^{+}$Tregs can be or emerge from memory cells, challenging the dogma of memory cells being uniformly detrimental to graft survival and tolerance induction (50-54). Indeed, targeting CD45RC not only induced active Treg-mediated donor alloantigen-specific tolerance (i.e., no signs of chronic allograft rejection, inhibition of anti-donor humoral responses), but also preserved immunity toward new exogenous antigens and memory responses. Additionally, we observed that after depletion of the $\mathrm{CD} 45 \mathrm{R} \mathrm{C}^{\text {high }}$ cells, the number of lymphoid cells that express $\mathrm{CD} 45 \mathrm{RC} \mathrm{C}^{\text {low } / \text { in }}$ in fact increased, suggesting that they may have proliferated. In the case of $\mathrm{CD} 4^{+}$and $\mathrm{CD} 8^{+}$Tregs, this could have been due to activation through recognition of donor alloantigens, but it could also have been due to a compensatory homeostatic proliferation following depletion of CD45RC ${ }^{\text {high }}$ cells; this could have affected other lymphoid populations, such as B, NK, and NKT cells. Surprisingly, we observed little effect of anti-CD45RC mAb on non-T cells. B cells were not susceptible to anti-CD45RC-mediated cell death induction, suggesting that the decrease of B cells observed at day 10 in the BM could be due to migration of $\mathrm{B}$ cells from the $\mathrm{BM}$ to the periphery, rather than apoptosis. This difference of effect of anti-CD45RC on lymphocyte subpopulations and monocytes could be due to differences of isoform expression; indeed, B cells all express higher molecular mass form (CD45RABC together) than $\mathrm{T}$ cells (8). Additionally, differences on signal transduction between $\mathrm{T}$ and $\mathrm{B}$ cells likely exist, since in CD45RC-deficient mice - in contrast to T cells - B cell development was not affected by the lack of CD45RC, suggesting that B cells do not require CD45 expression for maturation (55). We determined that the anti-rat CD45RC OX22 induced tolerance and showed high killing activity in vitro. This is reminiscent to anti-CD45RB mAb effects, since comparison of two different anti-CD45RB mAb showed that the one effective for prolonging allograft survival was also more effective in killing cells through apoptosis $(43,56-58)$. A chimeric mAb binding to both $\mathrm{CD} 45 \mathrm{RB}$ and CD45RO has been described to 
prevent islet allograft rejection in mice through depletion of memory T cells (57). To understand how transient anti-CD45RC mAb treatment favors immune-regulation through potentiation of both $\mathrm{CD} 4^{+}$ and $\mathrm{CD}^{+}$Tregs, analyses of their transcriptomic profile in long-term tolerant recipients showed that a number of Treg-associated genes involved in their stability, function, or migration were significantly upregulated, more particularly in $\mathrm{CD}^{+}$Tregs. We also demonstrated a distinct signature of $\mathrm{CD}^{+}$and $\mathrm{CD}^{+} \mathrm{CD} 45 \mathrm{RC}^{\text {low/- }}$ Tregs involving expression of the transcriptional regulators, suggesting an epigenetic regulation of immune memory related to Treg tolerance to donor.

This, together with the increased suppressive activity of Tregs when adoptively transferred or used in vitro, indicates that their function is likely increased through activation on alloantigens.

Thus, using three distinct strategies (i.e., CD40Ig, donor-derived peptides, or anti-CD45RC mAb in the present article; refs. 18 and 21), we have been able to expand and enhance the suppressive capacity of $\mathrm{CD} 8{ }^{+} \mathrm{CD} 45 \mathrm{RC}^{\text {low/- }}$ Tregs, and we have been able to demonstrate their potential in transplantation tolerance. However, with CD40Ig or donor-derived peptide treatments, we did not observe expansion or increased function for $\mathrm{CD} 4{ }^{+}$Tregs. In addition, here we observed the total absence of chronic rejection and anti-donor humoral responses, in contrast to CD40Ig-treated cardiac graft recipients, suggesting that anti$\mathrm{CD} 45 \mathrm{RC} \mathrm{mAb}$ therapy is more potent at controlling immune responses and has a higher potential in clinic.

Taken together, our study provides the first proof of concept for the potential of proapoptotic anti$\mathrm{CD} 45 \mathrm{RC} \mathrm{mAb}$ to eliminate effector cells in transplantation and promote specific allogeneic tolerance through donor-specific Treg potentiation. We demonstrated that transient CD45RC targeting resulted in sustained transcriptomic changes in $\mathrm{CD}^{+}$and $\mathrm{CD} 8^{+}$Tregs, able to adoptively transfer dominant tolerance. Anti-CD45RC treatment alone was sufficient to inhibit, not only acute rejection to solid organ and GVHD, but also chronic rejection, a major goal in transplantation. Thus, CD45RC-specific antibody is a promising therapeutic strategy to control immune responses in transplantation, as well as in other pathological situations where an increase of $\mathrm{CD}^{+}$and $\mathrm{CD} 8^{+}$Treg would be required.

\section{Methods}

Animals and cardiac transplantation model. Heart allotransplantation was performed between whole MHCincompatible male LEW-1W and LEW-1A rats as previously described $(18,59)$. Brown Norway $(B N)$ rat was used as third-party donor (Janvier Labs). Heart survival was evaluated by palpation through the abdominal wall and heart beating was graded from +++ to - . Followup was performed in blind conditions until graft rejection, when possible. Groups of 3-11 animals were treated. Rats used were matched in age (8-12 week old) and randomly treated or not.

GVHD induction in vivo. $1.5 \times 10^{7} \mathrm{PBMCs}$ or equivalent number of FACS-Aria-sorted CD45RC PBMCs from healthy volunteers (HVs) donor were injected intravenously in 10- to 13-week-old NSG SCID mice (Charles River Laboratories and in house) treated 16 hours earlier with whole-body sublethal irradiation of $2 \mathrm{~Gy}$. Recipients received anti-CD45RC mAb or an irrelevant control mAb starting day 0 until day 20 and every 2.5 days at $0.8 \mathrm{mg} / \mathrm{kg} /$ injection i.p. Recipients were weighted every day and sacrificed when percentage of weight loss was $\geq 20 \%$ of their initial weight. Followup was performed in blind conditions, when possible. Groups of 3-6 animals were treated. Mice were matched in sex, age, and initial weight and randomly treated or not.

Anti-CD45RC administration. The OX22 (IgG1 mouse, European Collection of Authenticated Cell Culture [ECACC]) hybridoma was used to produce the anti-rat CD45RC antibody. The anti-human CD45RC $\mathrm{mAb}$ (mouse IgG1, MT2 clone) was purchased from Mast Diagnostic. Mouse IgG1 anti-human CD16, with no cross-reaction with the rat (3G8 clone, homemade from hybridoma, ECACC) and mouse IgG1 purified Ab (107.3 clone, BD Biosciences) were used as controls for OX22 and MT2, respectively. All antibodies were given at a dose of $0.8 \mathrm{mg} / \mathrm{kg} / 2.5$ days i.v. from day 0 to 5,10 , or 20 after transplantation to rats and i.p. from day 0-20 after PBMC injection to NSG mice.

Histopathology studies. Tissue specimens were analyzed for chronic rejection at day 120 after transplantation as previously described. Briefly, tissues were fixed in paraformaldhehyde, paraffin embedded, cut in 5 $\mu \mathrm{m}$-thick sections, and stained with hematoxylin-eosin-saffron by the MicroPicell platform (60).

Lymphocyte preparation, isolation of subpopulations, and adoptive transfers. Rat spleens were harvested at day 120 , and splenocytes or subpopulations were purified as previously described (18, 23). Cell transfers were performed by i.v. injection of total splenocytes $\left(1.5 \times 10^{8}\right)$ or purified subpopulations $\left(5 \times 10^{6}\right.$ $\mathrm{CD}^{+} \mathrm{CD} 45 \mathrm{RC}^{\text {low } /-} \mathrm{T}$ cells, $4 \times 10^{6} \mathrm{CD} 8^{+} \mathrm{CD} 45 \mathrm{RC}^{\text {low } /-} \mathrm{T}$ cells, and $5 \times 10^{6} \mathrm{~B}$ cells $)$ in sublethally irradiated 
(4.5 Gy day -1) LEW.1A recipients grafted with the heart from a LEW.1W donor or from a Brown Norway rat $(\mathrm{BN})$ third-party donor, on the day of transplantation. Blood from HVs was collected by the Etablissement Français du Sang. Informed consent was obtained from all subjects. PBMCs were isolated by Ficoll-Paque density gradient centrifugation (Eurobio) at $760 \mathrm{~g}$ for 20 minutes at room temperature (RT) without brake and washed in PBS; remaining red cells were lysed by a hypotonic solution, and platelets were removed by a 10 minute, $430 \mathrm{~g}$ centrifugation. $1.5 \times 10^{7} \mathrm{PBMCs}$ or equivalent number of CD45RC sorted cells were i.v. injected to NSG mice.

Monoclonal antibodies and staining. Rat $\mathrm{T}$ cells and $\mathrm{pDC}$ were purified and sorted as previously described (21). Flow cytometry and cell sorting were performed using antibodies directed to T cells (TCR $\alpha \beta$, clone $\mathrm{R} 7 / 3$ ), $\mathrm{CD}^{+} \mathrm{CD} 25^{-} \mathrm{T}$ cells (clones OX35 and OX39), $\mathrm{CD} 8^{+}$or $\mathrm{CD} 4^{+} \mathrm{CD} 45 \mathrm{RC}^{\text {low/- }} \mathrm{T}$ cells (clones OX8 and OX22, OX32 or $3 \mathrm{H} 1437$ ), Foxp3 $3^{+}$cells (clone FJK-16s), CD4 ${ }^{+} \mathrm{CD} 45 \mathrm{R}^{+} \mathrm{pDCs}$ (clones OX35 and His24), $\mathrm{CD}_{103}{ }^{+} \mathrm{cDCs}$ (clones OX62 and OX35), CD11b/c $\mathrm{c}^{+}$monocytes (clone OX42), CD161 ${ }^{\text {high }} \mathrm{NK}$ cells (clone

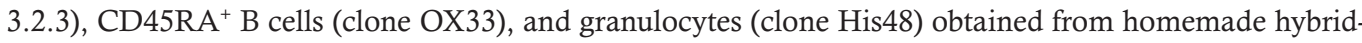
oma from the ECACC, except for 3H1437 clone from Santa Cruz Biotechnology and clone FJK-16s from eBioscience (Gating strategy in Supplemental Figure 1). All biotin-labeled mAb were visualized using Strepavidin-PE-Cy7 (BD Biosciences). Anti-human CD45RC mAb (clone MT2, IQ Product) was used to sort CD45RC- PBMCs from $\mathrm{HV}$ donor for GVH experiments.

Human $\mathrm{CD}^{+}$and $\mathrm{CD}^{+} \mathrm{T}$ cells and $\mathrm{B}$ cells were analyzed for CD45 isoform expression by using antiCD45RA (T6D11 clone, Miltenyi Biotec), anti-CD45RB (MT4 clone, BD Biosciences, or MEM143 clone, R\&D Systems), anti-CD45RC (MT2 clone, IQ Product), and anti-CD45RO (UCHL1 clone, BD Biosciences) after being gated on $\mathrm{CD}^{+}$cells (SK7 clone, BD Biosciences); CD4 ${ }^{+}$(RPAT4 clone, BD Biosciences) or $\mathrm{CD}^{+}$(BW135/80 clone, Miltenyi Biotec) cells, Foxp3 ${ }^{+}$(259D/C7, BD Biosciences) CD127 low $(\mathrm{HIL}-$ 7R-M21 clone, BD Biosciences) CD25+ (M-A251 clone, BD Biosciences) cells, B cells (CD19+ cells, HIB19 clone, BD Biosciences), NK cells (B159 clone, BD Biosciences), or NKT cells (B159 and SK7 clones, BD Biosciences); or on monocytes CD14+ (M5E2 clone, BD Biosciences) or CD16+ (3G8 clone, BD Biosciences) among living cells (DAPI negative).

A Canto II cytometer (BD Biosciences) was used to measure fluorescence, a FACS Aria II (BD Biosciences) was used to sort cells, and data were analyzed using the FLOWJO software (Tree Star Inc.). Cells were first gated by their morphology excluding dead cells by selecting DAPI-viable cells.

3' Digital gene expression (3'DGE) RNA-sequencing. Total RNA was isolated using the RNeasy-Mini Kit (Qiagen) and was processed for RNA-sequencing. According to Cacchiarelli et al., 3'DGE RNA-sequencing protocol was performed (61). Briefly, the libraries were prepared from $10 \mathrm{ng}$ of total RNA. The mRNA poly(A) tail is tagged with universal adapters, well-specific barcodes, and unique molecular identifiers (UMIs) during template-switching reverse transcriptase. Barcoded cDNAs from multiple samples are then pooled, amplified, and tagmented using a transposon-fragmentation approach, which enriches for $3^{\prime}$ ends of cDNA. A library of $350-800 \mathrm{bp}$ is run on an Illumina HiSeq using a TruSeq Rapid SBS Kit.

Read pairs used for analysis matched the following criteria: all 16 bases of the first read must have quality scores of at least 10, and the first 6 bases correspond exactly to a designed well-specific barcode. The second reads were aligned to RefSeq rat mRNA sequences (rn6) using Burrows-Wheeler Aligner version 0.7.4 with nondefault parameter "-1 24". Reads mapping to several positions into the genome are filtered out from the analysis. DGE profiles are generated by counting for each sample, the number of unique UMIs associated with each RefSeq genes.

Counts matrix was normalized with the $\mathrm{R}$ package DESeq2 (Bioconductor). DESeq2 parameters were adjusted to reduce influence of the sequencing run on the variability between samples. Differentially expressed genes were determined using the contrast function, with secondary testing (FDR) to obtain $q$ value. Genes were considered differentially expressed if the FDR $q$ value $<0.05$. Expression profile was drawn with ComplexHeatmap library (Bioconductor). Samples were ordered by condition, genes by origin of differential expression then by unsupervised clustering. Rlog function (DEseq2) was applied on normalized expression to fit a logarithmic scale. Finally, expression was centered for each gene by initial sequencing run of the samples. Volcano plot were drawn by plotting $-\log _{10}$ ( $q$ value) in function of $\log _{2}$ (fold-change) for contrast between naive/tolerant CD4 (left) and naive/tolerant CD8 (right). Genes were highlighted when absolute value of $\log _{2}$ (fold-change) was superior to 1 and $q$ value inferior to 0.05 .

Mixed lymphocyte reaction and suppressive assay. Naive Lewis $1 \mathrm{~A} \mathrm{CD} 4^{+} \mathrm{T}$ cells, naive Lewis $1 \mathrm{~W}$ allogeneic $\mathrm{pDC}$, and treated-syngeneic Lewis $1 \mathrm{~A} \mathrm{CD} 8^{+} \mathrm{CD} 45 \mathrm{RC}^{\text {low/- }}$ Treg or $\mathrm{CD} 4^{+} \mathrm{CD} 45 \mathrm{RC}^{\text {low } /-}$ Treg subsets were 
sorted as previously described (22). CD4 ${ }^{+}$Tregs were labeled with CPD450 before coculture. Proliferation of CFSE-labeled CD4 ${ }^{+} \mathrm{CD} 25^{-} \mathrm{T}$ cells was analyzed by flow cytometry after 6 days of culture, by gating on $\mathrm{TCR}^{+} \mathrm{CD}^{+}{ }^{+} \mathrm{CPD} 450^{-}$cells (R7/3-APC, Ox35-PECY7) among living cells (DAPI negative).

Antibody detection. Donor spleens were digested by collagenase D and stopped with EDTA $0.01 \mathrm{mM}$ (Sigma-Aldrich), and red cells were lysed. Serum of recipients were harvested at days 0, 4, 10, 15, and 120 and frozen until $\mathrm{Ab}$ assessment. Sera were added to donor splenocytes at a dilution 1/10, 1/30, 1/90, and 1/270 and incubated with either anti-rat IgG-FITC (Jackson ImmunoResearch), anti-rat IgG1 (MCA 194, Bio-Rad), anti-rat IgG2a (MCA 278, Bio-Rad), or anti-rat IgG2b (STAR114F, BioRad) and anti-Ms Ig-FITC (115-095-164, Jackson ImmunoResearch). A FACS Canto (BD Biosciences) was used to measure fluorescence, and data were analyzed using the FLOWJO software (Tree Star Inc.). Geometric mean of fluorescence (MFI) of tested sera was divided by mean of 5 naive Lewis $1 \mathrm{~A}$ sera MFI as control.

Cell death assessment. Splenocytes or T cells, purified by negative selection, from rats were incubated with medium, isotype control $\mathrm{Ab}$ (clone $3 \mathrm{G} 8,10 \mu \mathrm{g} / \mathrm{ml}$ ), dexamethasone $(20 \mu \mathrm{g} / \mathrm{ml}$ ), or anti-CD45RC (clone OX22, $10 \mu \mathrm{g} / \mathrm{ml}$ ) for 10 minutes to 18 hours. Then, cells were stained with anti-TCR $\alpha \beta$ (clone R7/3), anti-CD11b/c ${ }^{+}$monocytes (clone OX42), anti-CD45R (a B marker; clone OX33), anti-CD45RC (3H1437), annexin V (BD Biosciences) and DAPI. Percentage of late apoptosis was obtained by gating on $\mathrm{DAPI}^{+}$annexin $\mathrm{V}^{+}$cells among $\mathrm{CD} 45 \mathrm{RC}^{+} \mathrm{T}$ or non-T cells by flow cytometry. Mitochondrial membrane potential was evaluated after 10-minute incubation with $50 \mathrm{nM}$ of $\mathrm{DiOC}_{6}$ (3'3-Dihexyloxacarbocyanine iodide, ENZ-52303, Enzo Life Sciences) (62) by gating on DAPI-TCR ${ }^{+}$cells.

Human PBMCs were incubated with medium, isotype control Ab (Ms IgG1, clone 107.3, $10 \mu \mathrm{g} / \mathrm{ml}$ ), ATG (Thymoglobuline, Sanofi, $20 \mu \mathrm{g} / \mathrm{ml}$ ) or anti-CD45RC (Ms IgG1, clone MT2, $10 \mu \mathrm{g} / \mathrm{ml}$ ) for $10 \mathrm{~min}$ utes to 18 hours. Then, cells were stained with anti-CD3 (clone SK7, BD Biosciences), annexin V, and DAPI. Percentage of apoptosis was obtained by gating on DAPI ${ }^{+}$annexin $\mathrm{V}^{+}$cells among $\mathrm{T}$ or non-T cells by flow cytometry.

Immunization and detection of anti-KLH antibodies and anti-HRBC antibodies. KLH (Sigma-Aldrich) was injected at 3 or 120 days after transplantation in the footpad (50 $\mu$ g emulsified in $200 \mu 1$ of complete Freund's adjuvant; Sigma-Aldrich). Anti-KLH IgM and IgG Ab were detected, respectively, at day 4 and day 13 after immunization by ELISA as previously described (20).

Heart allografted recipients were first injected with HRBCs $\left(1 \times 10^{9} \mathrm{HRBC}\right.$ in $\left.800 \mu \mathrm{PBS}\right)$ i.v. at day -7 and treated 10 days from the day of transplantation with either anti-CD45RC mAb (clone OX22) or control monoclonal Ab (clone 3G8). They were secondly injected with HRBC the day of the transplantation. Sera were taken 4 days following the second injection for IgM detection and at day $-7,0,3,7$, and 13 for $\operatorname{IgG}$ assessment. Heat-inactivated sera were two-fold diluted from 1/10 to 1/640 and incubated with HRBC followed by incubation with anti-IgM FITC or anti-IgG FITC mAb. Signal was detected in DAPI' viable cells by flow cytometry.

Humoral response against mouse IgG1 was quantified by ELISA, by adding serum from anti-CD45RC or isotype control $\mathrm{mAb}$-treated recipients harvested 3 days after arrest of the treatment, as compared with serum from naive rats, on coated mouse IgG1 after FCS blocking. Rat IgG were detected by using biotinylated anti-rat IgG and HRP-streptavidin.

Statistics. Two-way repeated measures ANOVA test was applied for antibodies analysis, coculture, cytotoxicity experiments, and weight evolution followup. One-way repeated measures ANOVA Friedman test and Dunn's post-test were used to analyze phenotypes and cytotoxicity experiments. Mantel Cox Log Rank test was used to analyze survival curves. Adapted controls were performed together with the test conditions. Animal numbers were determined with ethical committee agreement.

Study approval. The experiments were approved by the ethical committee for animal experimentation under relevant institutional authorization ("Ministère de l'éducation nationale, de l'enseignement supérieur et de la recherche", Paris, France) APAFIS 2525 and APAFIS 3143.

\section{Author contributions}

EP, SB, and LB designed and performed experiments and analyzed data; EA, SK, BM, VD, and AD performed experiments; DM, EC, and LD analyzed data; and CG and IA funded the research, designed experiments, analyzed data, and wrote the paper. 


\section{Acknowledgments}

We thank Jeffrey Bluestone, Jonathan Bromberg, and Maria-Cristina Cuturi for critically reading the manuscript; Emmanuel Merieau for technical assistance; the Genomics and Bioinformatics Core Facility of Nantes (Biogenouest); and Aurélie Lardenois. We thank the Fondation Progreffe for financial support and Crédit Agricole for the donation of the FACS Aria. This work was realized in the context of the Labex IGO project (ANR-11-LABX-0016-01) and IHU-Cesti project (ANR-10-IBHU-005), which are part of the Investissements d'Avenir ANR French Government program. The IHU-Cesti project is also supported by Nantes Métropole and Région Pays-de-la-Loire. This work was supported by the Agence de la Biomedecine to CG, DHU Oncogreffe to CG and IA, Inserm-Region Pays-de-la-Loire to LB, and FRM and Progreffe to SK.

Address correspondence to: Carole Guillonneau or Ignacio Anegon, INSERM UMR1064 - Center for Research in Transplantation and Immunology-ITUN, 30 Bd Jean Monnet, 44093, Nantes Cedex 01, France. Phone: 33.2.40087410; E-mail: carole.guillonneau@univ-nantes.fr (CG); ignacio.anegon@univ-nantes.fr(IA).

1. Waldmann H, Cobbold S. Exploiting tolerance processes in transplantation. Science. 2004;305(5681):209-212.

2. Chan AC, Carter PJ. Therapeutic antibodies for autoimmunity and inflammation. Nat Rev Immunol. 2010;10(5):301-316.

3. Papotto PH, Marengo EB, Sardinha LR, Goldberg AC, Rizzo LV. Immunotherapeutic strategies in autoimmune uveitis. Autoimmun Rev. 2014;13(9):909-916.

4. Vierboom MP, et al. Clinical efficacy of a new CD28-targeting antagonist of T cell co-stimulation in a non-human primate model of collagen-induced arthritis. Clin Exp Immunol. 2016;183(3):405-418.

5. Hermiston $\mathrm{ML}, \mathrm{Xu} \mathrm{Z}$, Weiss A. CD45: a critical regulator of signaling thresholds in immune cells. Annu Rev Immunol. 2003;21:107-137.

6. Zamoyska R. Why is there so much CD45 on T cells? Immunity. 2007;27(3):421-423.

7. Chang VT, et al. Initiation of T cell signaling by CD45 segregation at 'close contacts'. Nat Immunol. 2016;17(5):574-582

8. Streuli M, Hall LR, Saga Y, Schlossman SF, Saito H. Differential usage of three exons generates at least five different mRNAs encoding human leukocyte common antigens. J Exp Med. 1987;166(5):1548-1566.

9. Thomas ML. The leukocyte common antigen family. Annu Rev Immunol. 1989;7:339-369.

10. Ordonez L, Bernard I, L'faqihi-Olive FE, Tervaert JW, Damoiseaux J, Saoudi A. CD45RC isoform expression identifies functionally distinct $\mathrm{T}$ cell subsets differentially distributed between healthy individuals and AAV patients. PLoS One. 2009;4(4):e5287.

11. Birkeland ML, Johnson P, Trowbridge IS, Puré E. Changes in CD45 isoform expression accompany antigen-induced murine T-cell activation. Proc Natl Acad Sci USA. 1989;86(17):6734-6738.

12. Altin JG, Sloan EK. The role of CD45 and CD45-associated molecules in T cell activation. Immunol Cell Biol. 1997;75(5):430445 .

13. Rocha B, Tanchot C. CD8 T cell memory. Semin Immunol. 2004;16(5):305-314.

14. Rogers PR, Pilapil S, Hayakawa K, Romain PL, Parker DC. CD45 alternative exon expression in murine and human CD4+ T cell subsets. J Immunol. 1992;148(12):4054-4065.

15. Spickett GP, Brandon MR, Mason DW, Williams AF, Woollett GR. MRC OX-22, a monoclonal antibody that labels a new subset of $\mathrm{T}$ lymphocytes and reacts with the high molecular weight form of the leukocyte-common antigen. J Exp Med. 1983;158(3):795-810.

16. Xystrakis E, Bernard I, Dejean AS, Alsaati T, Druet P, Saoudi A. Alloreactive CD4 T lymphocytes responsible for acute and chronic graft-versus-host disease are contained within the CD45RChigh but not the CD45RClow subset. Eur J Immunol. 2004;34(2):408-417.

17. Xystrakis E, et al. Identification of a novel natural regulatory CD8 T-cell subset and analysis of its mechanism of regulation. Blood. 2004;104(10):3294-3301.

18. Guillonneau C, et al. CD40Ig treatment results in allograft acceptance mediated by CD8CD45RC T cells, IFN-gamma, and indoleamine 2,3-dioxygenase. J Clin Invest. 2007;117(4):1096-1106.

19. Powrie F, Mason D. OX-22high CD4+ T cells induce wasting disease with multiple organ pathology: prevention by the OX-22low subset. J Exp Med. 1990;172(6):1701-1708.

20. Guillot C, et al. Prolonged blockade of CD40-CD40 ligand interactions by gene transfer of CD40Ig results in long-term heart allograft survival and donor-specific hyporesponsiveness, but does not prevent chronic rejection. J Immunol. 2002;168(4):1600-1609.

21. Picarda E, et al. MHC-derived allopeptide activates TCR-biased CD8+ Tregs and suppresses organ rejection. J Clin Invest. 2014;124(6):2497-2512.

22. Li XL, et al. Mechanism and localization of CD8 regulatory T cells in a heart transplant model of tolerance. J Immunol. 2010;185(2):823-833.

23. Bézie S, Picarda E, Ossart J, Martinet B, Anegon I, Guillonneau C. Compensatory Regulatory Networks between CD8 T, B, and Myeloid Cells in Organ Transplantation Tolerance. J Immunol. 2015;195(12):5805-5815.

24. Bézie S, et al. Fibrinogen-like protein 2/fibroleukin induces long-term allograft survival in a rat model through regulatory B cells. PLoS ONE. 2015;10(3):e0119686.

25. Ordonez L, et al. A higher risk of acute rejection of human kidney allografts can be predicted from the level of CD45RC expressed by the recipients' CD8 T cells. PLoS ONE. 2013;8(7):e69791. 
26. Hua J, Davis SP, Hill JA, Yamagata T. Diverse Gene Expression in Human Regulatory T Cell Subsets Uncovers Connection between Regulatory T Cell Genes and Suppressive Function. J Immunol. 2015;195(8):3642-3653.

27. Louvet $\mathrm{C}$, et al. Identification of a new member of the CD20/FcepsilonRIbeta family overexpressed in tolerated allografts. Am $J$ Transplant. 2005;5(9):2143-2153.

28. Hawiger D, Wan YY, Eynon EE, Flavell RA. The transcription cofactor Hopx is required for regulatory T cell function in dendritic cell-mediated peripheral T cell unresponsiveness. Nat Immunol. 2010;11(10):962-968.

29. Probst-Kepper M, et al. GARP: a key receptor controlling FOXP3 in human regulatory T cells. J Cell Mol Med. 2009;13(9B):3343-3357.

30. Sempowski GD, Cross SJ, Heinly CS, Scearce RM, Haynes BF. CD7 and CD28 are required for murine CD4+CD25+ regulatory $\mathrm{T}$ cell homeostasis and prevention of thyroiditis. J Immunol. 2004;172(2):787-794.

31. Kleinewietfeld M, Puentes F, Borsellino G, Battistini L, Rötzschke O, Falk K. CCR6 expression defines regulatory effector/ memory-like cells within the CD25(+)CD4+ T-cell subset. Blood. 2005;105(7):2877-2886.

32. Glatigny S, Duhen R, Arbelaez C, Kumari S, Bettelli E. Integrin alpha L controls the homing of regulatory T cells during CNS autoimmunity in the absence of integrin alpha 4. Sci Rep. 2015;5:7834

33. Taraban VY, Ferdinand JR, Al-Shamkhani A. Expression of TNFRSF25 on conventional T cells and Tregs. J Clin Invest. 2011;121(2):463-4; author reply 465.

34. Schreiber TH, et al. Therapeutic Treg expansion in mice by TNFRSF25 prevents allergic lung inflammation. J Clin Invest. 2010;120(10):3629-3640.

35. Mahmud N, Klipa D, Ahsan N. Antibody immunosuppressive therapy in solid-organ transplant: Part I. $m A b s$. 2010;2(2):148156

36. Afzali B, et al. Comparison of regulatory $\mathrm{T}$ cells in hemodialysis patients and healthy controls: implications for cell therapy in transplantation. Clin J Am Soc Nephrol. 2013;8(8):1396-1405.

37. Guillonneau C, et al. Anti-CD28 antibodies modify regulatory mechanisms and reinforce tolerance in CD40Ig-treated heart allograft recipients. J Immunol. 2007;179(12):8164-8171.

38. Guillonneau C, Picarda E, Anegon I. CD8+ regulatory T cells in solid organ transplantation. Curr Opin Organ Transplant. 2010;15(6):751-756.

39. Bézie S, et al. IL-34 is a Treg-specific cytokine and mediates transplant tolerance. J Clin Invest. 2015;125(10):3952-3964.

40. Luke PP, et al. Prolongation of allograft survival by administration of anti-CD45RB monoclonal antibody is due to alteration of CD45RBhi: CD45RBlo T-cell proportions. Am J Transplant. 2006;6(9):2023-2034

41. Chen G, et al. Anti-CD45RB monoclonal antibody prolongs renal allograft survival in cynomolgus monkeys. Am J Transplant. 2007;7(1):27-37.

42. Basadonna GP, et al. Antibody-mediated targeting of CD45 isoforms: a novel immunotherapeutic strategy. Proc Natl Acad Sci USA. 1998;95(7):3821-3826.

43. Lazarovits AI, et al. Prevention and reversal of renal allograft rejection by antibody against CD45RB. Nature. 1996;380(6576):717-720.

44. Molano RD, et al. Prolonged survival of allogeneic islet grafts in NOD mice treated with a combination of anti-CD45RB and anti-CD154 antibodies. Transplant Proc. 2001;33(1-2):248-249.

45. Rothstein DM, et al. Targeting signal 1 through CD45RB synergizes with CD40 ligand blockade and promotes long term engraftment and tolerance in stringent transplant models. J Immunol. 2001;166(1):322-329.

46. Abu-Hadid MM, Lazarovits AI, Madrenas J. Prevention of diabetes mellitus in the non-obese diabetic mouse strain with monoclonal antibodies against the CD45RB molecule. Autoimmunity. 2000;32(1):73-76.

47. Parry N, et al. Cyclosporine inhibits long-term survival in cardiac allografts treated with monoclonal antibody against CD45RB J Heart Lung Transplant. 1999;18(5):441-447.

48. Miyara M, et al. Functional delineation and differentiation dynamics of human CD4+ T cells expressing the FoxP3 transcription factor. Immunity. 2009;30(6):899-911.

49. Touzot F, et al. CD45RA depletion in HLA-mismatched allogeneic hematopoietic stem cell transplantation for primary combined immunodeficiency: A preliminary study. J Allergy Clin Immunol. 2015;135(5):1303-9.e1.

50. Chen W, Ghobrial RM, Li XC. The Evolving Roles of Memory Immune Cells in Transplantation. Transplantation. 2015;99(10):2029-2037.

51. Krupnick AS, et al. Central memory CD8+ T lymphocytes mediate lung allograft acceptance. J Clin Invest. 2014;124(3):1130-1143.

52. Li S, et al. A naturally occurring CD8(+)CD122(+) T-cell subset as a memory-like Treg family. Cell Mol Immunol. 2014;11(4):326-331.

53. Zhang X, Chang Li X, Xiao X, Sun R, Tian Z, Wei H. CD4(+)CD62L(+) central memory T cells can be converted to Foxp3(+) T cells. PLoS One. 2013;8(10):e77322.

54. Dai H, Wan N, Zhang S, Moore Y, Wan F, Dai Z. Cutting edge: programmed death-1 defines CD8+CD122+ T cells as regulatory versus memory T cells. J Immunol. 2010;185(2):803-807.

55. Kishihara K, et al. Normal B lymphocyte development but impaired T cell maturation in CD45-exon6 protein tyrosine phosphatase-deficient mice. Cell. 1993;74(1):143-156.

56. Luke PP, et al. Alteration in CD45RBhi/CD45RBlo T-cell ratio following CD45RB monoclonal-antibody therapy occurs by selective deletion of CD45RBhi effector cells. Transplantation. 2003;76(2):400-409.

57. Gregori S, et al. An anti-CD45RO/RB monoclonal antibody modulates $\mathrm{T}$ cell responses via induction of apoptosis and generation of regulatory T cells. J Exp Med. 2005;201(8):1293-1305.

58. Parikh K, Poppema S, Peppelenbosch MP, Visser L. Extracellular ligation-dependent CD45RB enzymatic activity negatively regulates lipid raft signal transduction. Blood. 2009;113(3):594-603.

59. Josien R, Heslan M, Brouard S, Soulillou JP, Cuturi MC. Critical requirement for graft passenger leukocytes in allograft tolerance induced by donor blood transfusion. Blood. 1998;92(12):4539-4544.

60. Guillonneau C, et al. The role of TNF-related activation-induced cytokine-receptor activating NF-kappa B interaction in acute 
allograft rejection and CD40L-independent chronic allograft rejection. J Immunol. 2004;172(3):1619-1629.

61. Cacchiarelli D, et al. Integrative Analyses of Human Reprogramming Reveal Dynamic Nature of Induced Pluripotency. Cell. 2015;162(2):412-424.

62. Chang H, Huang H, Huang T, Yang P, Wang Y, Juan H. Flow Cytometric Detection of Mitochondrial Membrane Potential. Bio-protocol. 2013;3(8): e430. https://doi.org/10.21769/BioProtoc.430. 